\title{
1 Internal slab-column connections under 2 monotonic and cyclic imposed rotations
}

4 ABSTRACT

5 Reinforced concrete flat slabs supported by slender columns are often used as gravity load resisting system for buildings in regions of moderate seismicity. Current codes of practice determine the displacement capacity of slab-column connections using empirical formulas which were calibrated against experimental studies. This article reviews and compares test configurations used in past experimental studies and presents the adopted configuration for an experimental investigation on 13 full-scale internal slab-column connections without transverse reinforcement. The objective of the test campaign was to assess the influence of the loading history (monotonic vs. reversed cyclic) for different gravity loads and reinforcement ratios. The study showed that cyclic loading led in particular for slabs subjected to low gravity

14 loads to significant moment strength and deformation capacity reduction when compared to results obtained from monotonic loading tests. The effect of cyclic loading was more pronounced for slabs with low reinforcement content. The experimental results are compared to the predictions of ACI-318, Eurocode 2 and fib-Model Code 2010. All codes predict the moment strength on the safe side. For the deformation capacity of the cyclic tests, only ACI318 provides estimates, which are, in average, accurate enough but unconservative for slabs subjected to high gravity loads.

\section{$21 \quad$ Keywords}

22 Slab-column connections; Seismic loading; Unbalanced moment; Deformation capacity;

23 Cyclic loading effect 


\section{1. Introduction}

2 In many countries with moderate seismicity, reinforced concrete (RC) flat slabs supported

3 on columns is one of the most commonly used structural systems for office and industrial

4 buildings since it features several advantages (large open floor spaces, limited thickness). To

5 increase the lateral stiffness and strength of the structure, RC walls are added which carry the

6 largest portion of the horizontal loads generated during earthquakes. Therefore, the slab-

7 column system does not contribute significantly to the lateral stiffness and strength of the

8 structure, but each slab-column connection must follow the seismically induced drifts of the

9 building while maintaining its capacity to transfer vertical loads from the slab to the columns.

10 As a result of the seismically induced drift, the slab-column connection is subjected to a

11 moment. Codes of practice determine the moment capacity of slab-column connections either

12 using the eccentric shear transfer model [1,2] or by reducing the control perimeter [3]. The

13 deformation capacity is estimated from empirical formulas [1] derived from past experimental 14 works [4].

15 Past studies investigated the seismic response of slab-column connections subjected to monotonic loading or to cyclic loading with increasing rotation amplitudes. Until today, only

17 three pairs of slabs were tested which investigated the impact of the loading history 18 (monotonic vs. reversed cyclic). Understanding the effect of the loading history is important 19 when developing mechanical models for the moment-rotation relationship of slab-column 20 connections including their rotation capacity. To contribute to the understanding of the impact 21 of the loading history on the response of slab-column connections, five pairs of slabs that 22 were subjected to monotonic and cyclic loading respectively were tested and provided several 23 important findings. These new pairs differed from the existing pairs mainly with regard to the 24 slab thickness (new: $250 \mathrm{~mm}$, existing: $76-90 \mathrm{~mm}$ ). 
This paper reviews the different experimental setup configurations adopted in past studies.

2 The setup configuration that was adopted for this study is compared to previous

3 configurations as well as demands obtained from the analysis of a prototype building. The

4 main results of the experimental campaign (comprising in total 13 tests) are presented along

5 with a discussion on the influence of the reinforcement ratio, gravity induced shear forces and

6 loading history (monotonic vs. cyclic) on the deformation capacity and punching strength of

7 slab-column connections without transverse reinforcement. The test results are also compared to the predictions of ACI-318 [1], Eurocode 2 [2] and fib-Model Code [3] in terms of moment resistance and deformation capacity.

\section{Simulation of slab-column connections under seismically-induced drifts}

\section{in the laboratory}

Space limitations in the laboratory often determine the size of test units. For this reason, most experimental campaigns study the behaviour of isolated slab-column connections that comprise one column and the surrounding slab and only few research groups opted for testing subassemblies of one interior and two exterior slab-column connections [5] or large-scale tests on single-storey [6,7] and multi-storey buildings with slab-column connections [8]. Since there are only very few tests on subassemblies, mechanical models have to be validated mainly against tests on isolated slab-column connections. For this reason, it is important to understand the approximations related to the testing of such isolated connections. To do so, the slab-column connection of a prototype building is analysed and its moment-slab rotation

21 relationship is used as benchmark for the curves obtained from different experimental setups.

22 These comprise setup configurations of previous experimental campaigns and an adapted setup configuration that is used in the experimental study presented in this paper. 


\subsection{Prototype building}

A five-storey office building typical for Central European construction served as reference

3 for the design of the test specimens of the performed experimental campaign. The slabs had a

4 thickness of $250 \mathrm{~mm}$ and internal spans of $6.8 \mathrm{~m}$. The storey height was $3.0 \mathrm{~m}$. The primary lateral load-resisting system comprised two RC C-shaped cores providing lateral strength and stiffness in both directions (Fig. 1), whereas slab-column connections were designed to carry only vertical loads. The design was performed according to the fib-Model Code [3] for moderate seismic zone. The columns were square and cast-in-place with a size of $390 \mathrm{~mm}$.

9 The top reinforcement ratio in each direction was equal to $0.75 \%$ in the zone of the slab near the column (grey zones) and $0.5 \%$ in the middle strip (white zones), as shown in Fig. 1.

11 Bottom reinforcement was provided in both directions over the whole slab, with a ratio equal to $0.375 \%$ around the column (dark grey zones) and $0.5 \%$ elsewhere. The provided bottom

13 flexural reinforcement was continuous over the slab-column connections, complying with the 14 integrity rules of ACI-318 [1]. The quasi-permanent vertical loads consisted of $6.25 \mathrm{kN} / \mathrm{m}^{2}$ of 15 self-weight of the slab, $1.00 \mathrm{kN} / \mathrm{m}^{2}$ superimposed load and $0.60 \mathrm{kN} / \mathrm{m}^{2}$ quasi-permanent live load. Under this load combination, the unfactored vertical load acting on an interior slabcolumn connection was approximately $40 \%$ of the punching strength according to ACI-318

18 [1] and Eurocode 2 [2] and 50\% of the punching strength according to fib-Model Code [3] using mean strength values without applying any safety factors. The assumed concrete compressive strength was $32 \mathrm{MPa}$ and the yield and maximum tensile stress of the reinforcing steel were $550 \mathrm{MPa}$ and $680 \mathrm{MPa}$, respectively. 


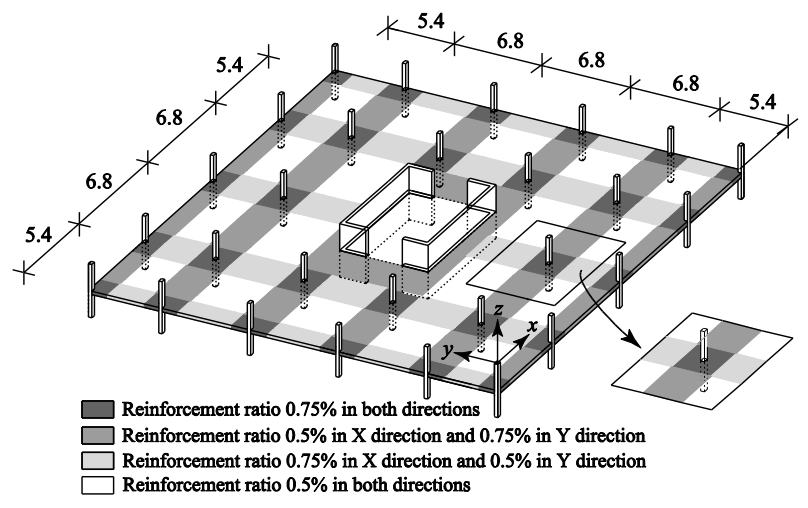

Fig. 1. Typical storey of the building that served as reference for the experimental campaign and top reinforcement ratios (dimensions in $\mathrm{m}$ ).

\subsection{Setup configurations of previous experimental research}

Most test programmes on the behaviour of slab-column connections subjected to an

3 unbalanced moment considered test specimens representing a single interior column and the

4 surrounding slab. The dimensions of the specimens for the monotonic tests were typically 5 chosen as $0.44 L \times 0.44 L$ where $L$ is the distance between column axes $[9,10,11]$. The distance $0.22 L$ corresponds for an elastic slab with constant stiffness and equal spans subjected to an evenly distributed vertical load to the distance of the point of contraflexure to the column axis. Most experimental campaigns focusing on the seismic response of slab-column

9 connections used slab elements of the size $1.0 \mathrm{Lx} 1.0 \mathrm{~L}$, i.e., from midspan to midspan of adjacent bays (e.g. [4, 12, 13] with few exceptions where larger elements were tested [14, $1115])$.

All past tests used one of the following test setups, which differed with regard to the kinematic boundary conditions and the way the vertical load was applied: restraining the vertical displacement of the slab ends [16, 17, 18, 21] (Fig. 2). 
- Setup (b): the unbalanced moment is introduced by applying additional vertical loads to the edges of the slab and by fixing the column stub ends [14, 11, 20] (Fig. 2).

- Setup (c): the unbalanced moment is introduced by applying a horizontal force to the top column stub and by restraining the vertical displacement of either the slab edges $[9$, $10,4,12,21,13,22,23,24,25]$ (Fig. 2) or specific locations on the slab surface [26] determined through finite element analysis to reproduce the internal actions of the prototype building [27]. The vertical load is applied either by jacks underneath the column stub $[24,26]$ or by weights on the slab surface $[12,13]$, with several campaigns combining both aforementioned ways of vertical load introduction [4, 23].
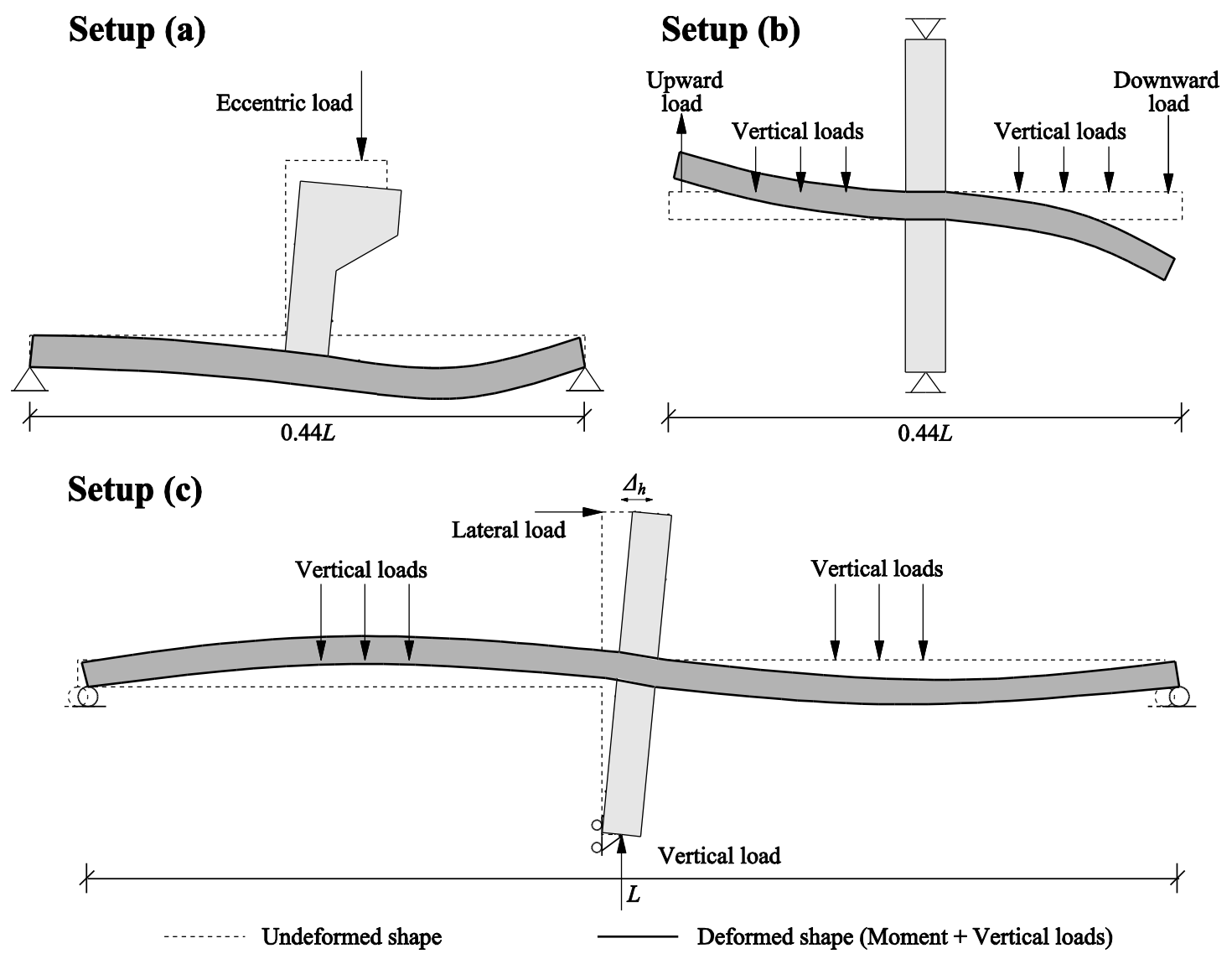

Fig. 2. Test setup configurations used in previous experimental campaigns for slab-column connections with seismic moment transfer.

11 Setup (a) is predominantly adopted to simulate unbalanced moments due to unequal spans.

12 The test setup is simple and easy to implement but when applied to simulate seismic loading, 
1 it is somewhat unrealistic as the ratio of inserted moment to applied vertical load on the slab-

2 column connection (subsequently referred to as eccentricity) remains constant. As a result, the 3 applied vertical load changes throughout the test.

4 Depending on the control of the actuators inducing the forces at the slab edges, setup (b)

5 can be used to simulate constant eccentricity [11], constant vertical load [14] or equal but

6 opposite slab deflections at the two opposite edges [20]. No additional reinforcement was

7 provided to the slab edges perpendicular to the unbalanced moment to account for the slab 8 part between $0.22 L$ and $0.5 L$.

9 Setup (c) is predominantly used for cyclic tests on slab-column connections. It is based on the assumption that for seismic actions the contraflexure points are located at midspan of the

11 slab. The test unit size and the reaction structure for the lateral load application impose 12 significant space requirements for laboratories and therefore the specimens are often tested at 13 reduced scale, i.e. specimens with thin slabs, with very few exceptions [10, 24, 25].

14

\subsection{Chosen setup configuration and loading procedure}

16 Fig. 3 shows a drawing of the setup that was chosen for this test campaign, which is 17 subsequently denoted as setup (b) mod since it is an evolution of setup (b). When compared to 18 setup (b), the unbalanced moment is introduced by additional upward and downward loads 19 located at $\sim 0.50 \mathrm{~L}$ from the column axis. The slab had only dimensions of $0.44 \mathrm{~L}$ while the 20 distance between the slab edge and $0.50 \mathrm{~L}$ was bridged by steel beams. A photo of the test 21 setup is shown in Fig. 4. 


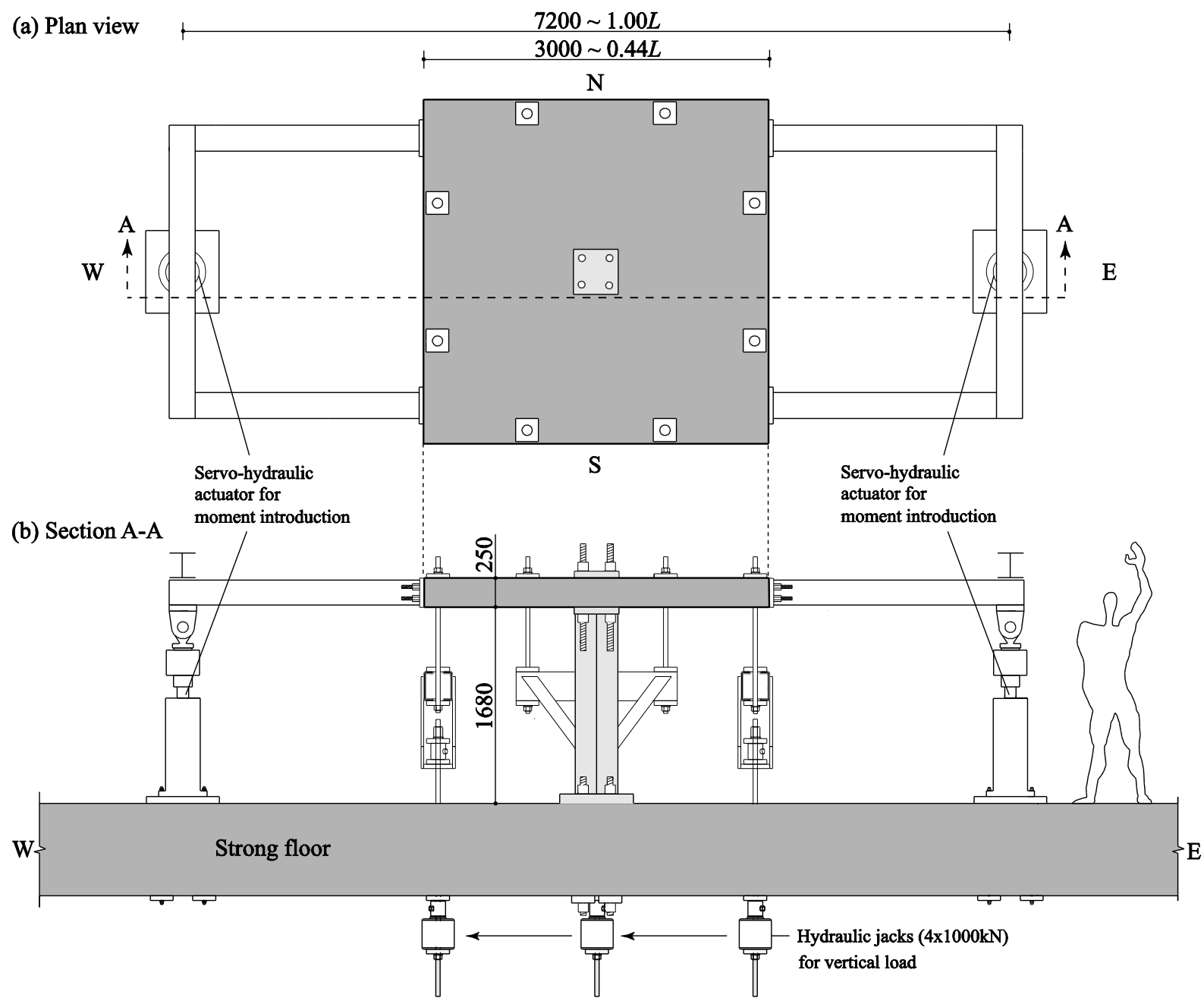

Fig. 3. Drawing of the setup (dimensions in mm): (a) plan view and (b) section A-A.

1 The column consisted of a welded steel profile and was clamped to the strong floor. Before

2 the zero measurements, the slab was clamped down onto the column by means of four

3 threaded bars $\Phi 50 \mathrm{~mm}$. They were each post-tensioned to a force of $1.2 \mathrm{MN}$ in order to limit

4 separation of the slab-column interface. Prestressing of the slab-column connection is

5 necessary for setup (b) to provide stability to the system [11,20]. Use of steel instead of RC

6 does not affect the behaviour of the connection as in both cases the column is designed to

7 remain elastic during the test [21]. A long as failure occurs outside the threaded bar-

8 reinforced region, it is not expected that this region affects the behaviour of the specimen

9 [19]. 
The vertical load was applied using four hydraulic jacks, each one connected to a steel beam

2 that distributed the load to two points on the slab surface. Its magnitude was kept constant by 3 controlling the oil pressure in the vertical loading jacks. The vertical loads were applied at a

4 radius of $1.504 \mathrm{~m}$, which corresponds to $0.22 \mathrm{~L}$, i.e. the radius where the radial moment of an 5 elastic homogenous slab subjected to a uniformly distributed vertical load is zero. These 6 vertical loads modelled all superimposed loads and the gravity loads of the slab part that was 7 not included in the test setup (0.22-0.50L).

8 The effects of seismically induced drifts were simulated by applying two equal and opposite vertical forces by means of two servo-hydraulic actuators (Fig. 3). The lever arm of the force couple was increased from $6.8 \mathrm{~m}$, which corresponds to the bay length of the prototype 11 building, to $7.2 \mathrm{~m}$ due to laboratory constraints. The actuators were connected to steel beams 12 that were in turn connected to the slab. Since the forces applied by the two servo-hydraulic actuators were equal and opposite, the shear force applied to the slab-column connection 14 remained constant.

15 For the quasi-static monotonic tests, the forces applied by the servo-hydraulic actuators were monotonically increased until failure. For the quasi-static cyclic tests, rotation cycles of 17 increasing amplitude were applied. The monitoring of the slab rotation was performed using inclinometers that were installed on the east and west slab edge $\left(\psi_{\max }\right.$ and $\left.\psi_{\min }\right)$. To obtain the slab-column connection rotation due to slab deformation alone $\left(\psi_{s c c}\right)$, the rotation due to column deformation and possible separation of the slab-column interface was measured using

21 rotation readings at the middle of the top surface of the slab $\left(\psi_{c o l}\right)$ and then subtracted from 22 the measured slab rotation:

$$
\psi_{s c c}=\frac{\psi_{\max }-\psi_{\min }}{2}-\psi_{c o l}
$$


The slab edges were reinforced with additional bars to account for the part of the slab that is

2 not represented by the test setup and to connect the slab to the steel beams for the moment

3 application. It will be shown in the following paragraph that this additional reinforcement was

4 crucial in order to obtain a good comparison between the moment-rotation relationship of the

5 prototype building and that of the test unit.

6

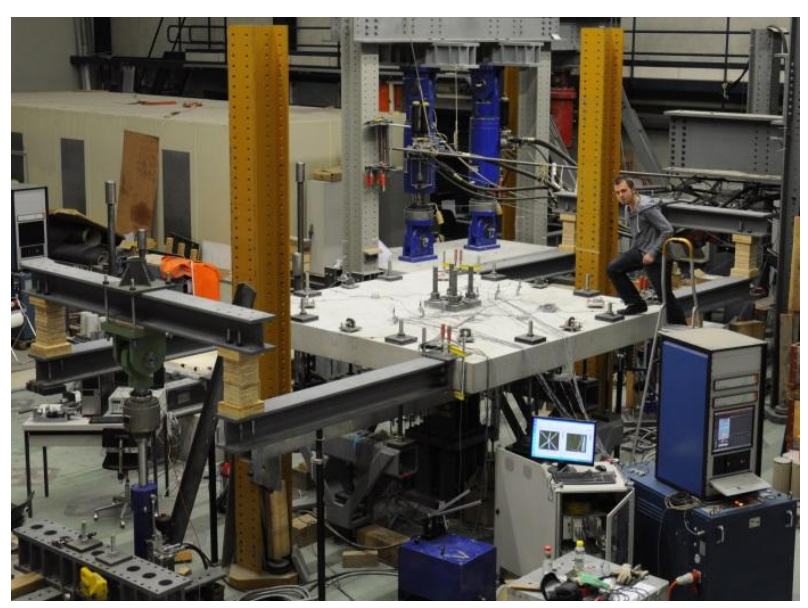

Fig. 4. Slab specimen in test setup

7

\subsection{Response comparison between setup configurations and prototype}

\section{building}

The setup configurations presented in Sections 2.2 and 2.3 are simplifications of the boundary conditions imposed on a flat slab in an actual building subjected to seismic excitation. The influence of the boundary conditions on the deformation capacity of slabcolumn connections has been demonstrated by previous numerical studies, under both vertical load [28] and combined vertical load and transferred moment [29]. It is therefore essential to evaluate the capacity of each setup to reproduce the behaviour of slab-column connections of the prototype building. To this end, the response of an internal slab-column connection of the prototype building and the response of isolated slab-column connections tested in setups (b), (c) and the chosen (b) mod were simulated using the program SAP2000 [30]. As discussed in 
1 Section 2.2, setup (a) is not suitable for reproducing the seismic response of slab-column

2 connections. Setup (a) was therefore only used for the validation of the numerical model but

3 not included in the evaluation of test setups. The slab was modelled using nonlinear layered

4 shell elements with a Mindlin-Reissner formulation to include transverse shear deformations.

5 Only elastic shear deformations were included; the model could therefore only predict the

6 nonlinear flexural response. The layered shell formulation adopted for the numerical

7 investigation uses smeared reinforcement. Fourteen integration points were used over the

8 height of the slab. The unconfined concrete model by Mander et al. [31] and the model by

9 Park and Paulay [32] were used for modelling the nonlinear behaviour of concrete and

10 reinforcing steel, respectively. The tensile strength of the concrete was assumed to be zero.

11 For evaluating the seismic performance of buildings in terms of displacements, structural 12 engineers use typically the interstorey drift $\psi_{s t}$, i.e., the relative horizontal displacement 13 between two adjacent floors divided by the storey height. In structural systems of flat slabs 14 and columns both the deformation of the slab and the column contribute to the interstorey 15 drift:

$$
\psi_{s t}=\psi_{c o l}+\psi_{s c c}+\psi_{\text {midspan }}
$$

where $\psi_{c o l}, \psi_{s c c}$ and $\psi_{\text {midspan }}$ are respectively the contributions of column deformation, slab deformation until $0.22 L$ (subsequently referred to as slab-column connection rotation), and slab deformation between $0.22 \mathrm{~L}$ and $0.50 \mathrm{~L}$. Since the present article focuses on the contribution of slab deformation to the interstorey drift, the columns were modelled as rigid $\left(\psi_{c o l}=0\right)$

To verify the numerical model, slab specimens tested in previous experimental campaigns were analysed and numerical results compared against experimental results. Fig. 5 shows the comparisons of the experimental and calculated curves for tests using setups (a) and (b) [20, 18] while Fig. 6 shows the same for tests using setup (c) $[4,12,26]$. For each test campaign, 
1 the contribution of the slab deformation to the interstorey drift was measured differently and

2 the comparison uses the deformation quantity reported. This is the central deflection for test

3 units P16A and P32A by Krüger [18], who used setup (a) (Fig. 5a, b). These test units were

4 chosen because of their high slenderness. Islam and Park [20], who used setup (b) (Fig. 5c)

5 for the test IP2, reported the slab-column connection rotation $\psi_{s c c}$. It was computed from the

6 deflections of the two slab edges orthogonal to the lateral load. Pan and Moehle [4],

7 Robertson et al. [12] and Tian et al. [26] used setup (c) (Fig. 6). For all these tests the deformations were described using the slab-column connection rotation, computed as the horizontal displacement of the rigid column divided by the storey height. Test units AP1 [4] and $1 \mathrm{C}[12]$ were chosen since they represent cases with limited and increased deformation

11 capacity, respectively, and similar reinforcement ratio with the prototype building. Test unit 12 L0.5 [26] was chosen since its column size is very close to the one adopted for the prototype building and the experimental campaign.

14 It should be noted that the finite element model captures only the nonlinear flexural response but cannot account for premature punching failure of the slab-column connections that can occur at a moment substantially lower than the yield moment. After punching failure, the shear deformations become significant, which is not accounted for in the numerical simulation. For this reason, the comparison of numerical and experimental response focuses on the prediction up to the experimental peak strength. A constant shear retention factor $\beta=$ 0.1 was chosen for the shear stiffness reduction before and after cracking since the focus was on the ultimate response rather than the initial response. Figs. 5 and 6 show that, although the loading and boundary conditions of the specimens differed substantially between the different setups (Section 2.2), the numerical analysis predicted the moment-deformation response between cracking and peak load rather well (note that the aim of the simulation was not to predict the ultimate strength but the moment-rotation response). 

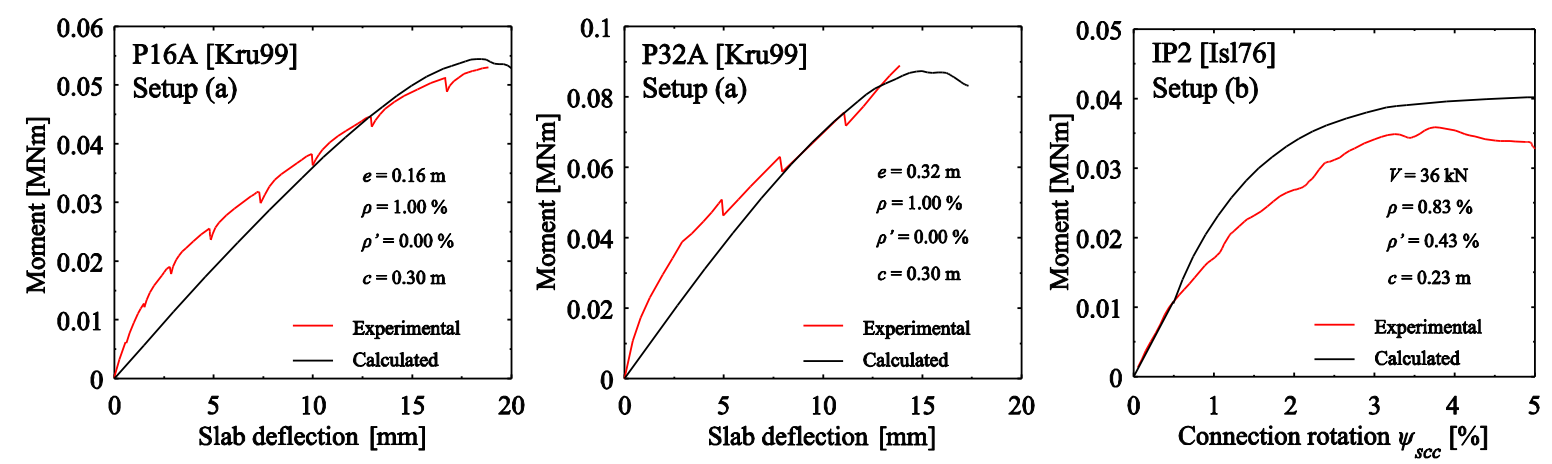

Fig. 5. Comparison of test results and numerical analyses for setup (a) and setup (b).
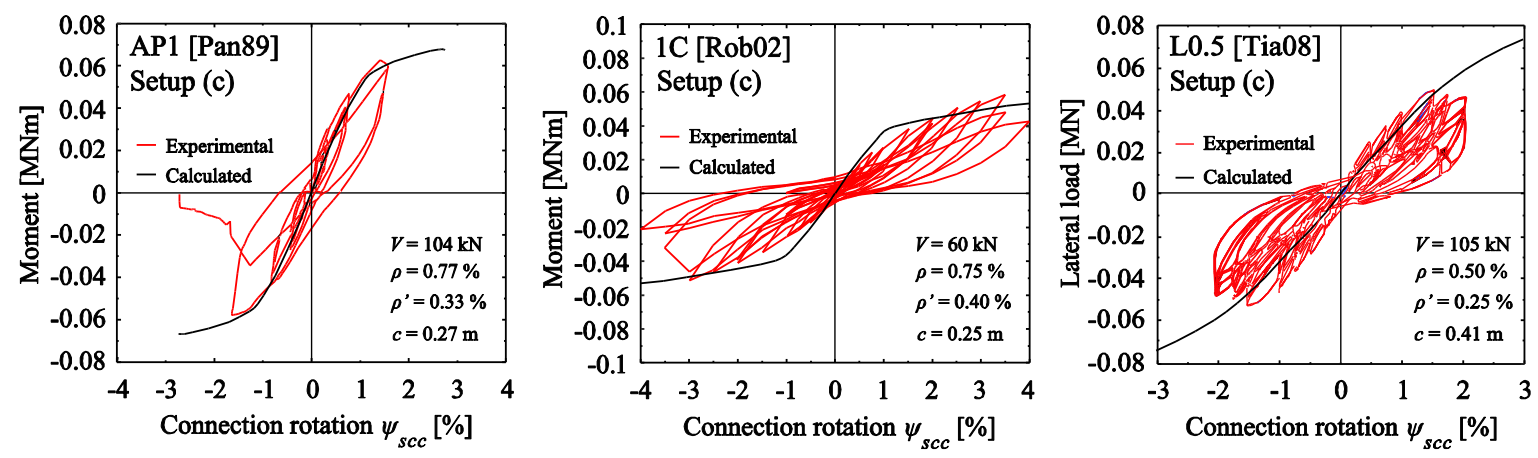

Fig. 6. Comparison of test results and numerical analyses for setup (c).

2 To simulate the behaviour of an internal slab-column connection in the prototype building

3 (Fig. 1), an element $L \times L$ with continuity boundary conditions (Fig. 7a) was analysed. The

4 moment at the slab-column connection was inserted through incrementally increasing lateral

5 loads at the top of the column stub while monitoring the rotation at the slab-column node. A

6 uniform gravity pressure $q_{V}$ was applied at the slab surface to simulate the vertical loads

7 specified in Section 2.1. The column member was modelled as rigid and was pinned at the

8 base $\left(\delta_{x, y, z}=0\right)$ and free at the top. The slab edges parallel to the $x$ axis were restrained against

9 rotation about the same axis $\left(\theta_{x}=0\right)$ whereas the other edges were constrained to have the

10 same vertical displacement $\left(\delta_{z}\right)$ and rotation about the $y$ axis $\left(\theta_{y}\right)$ as shown in Fig. 7a. Since

11 the column is rigid $\left(\psi_{c o l} \approx 0\right.$, Fig. $\left.7 \mathrm{a}\right)$, the slab rotation $\left(\psi_{s c c}+\psi_{\text {midspan }}\right)$ is equal to the

12 interstorey drift $\psi_{s t}$. The geometric and material properties as well as the slab reinforcement of

13 the element $L \times L$ with continuity boundary conditions are specified in Section 2.1. For 
1 consistency reasons, the models representing the test units for setups (b) $\bmod$, (b) and (c) were

2 assigned the same material properties and reinforcement ratios. The slab dimensions of setups

3 (b) and (b) mod were $0.44 \mathrm{~L}$ and that of setup (c) $1.0 \mathrm{~L}$.

4 The numerical model for setup (b) mod is shown in Fig. 7b. The moment at the slab-column 5 connection was introduced through a couple of incrementally increasing vertical forces with 6 amplitude $F_{V}$ applied to steel members that were in turn connected to the slab edges. The steel 7 members were modelled using elastic beam elements. The model of setup (b) mod included also 8 the additional reinforcement at the slab edges parallel to the $x$-axis (see Section 2.3). The 9 numerical model for setup (b) is similar to the one of the chosen setup, the only differences being the absence of the additional reinforcement along the slab edges and the smaller lever 11 arm of the applied vertical force couple $(0.44 L$ vs $1.0 L)$. Since for these two setups the 12 column rotation was zero, the analysis result is shown in terms of the slab-column connection rotation computed from the deflections at a distance of $0.22 L$ from the column centre $\left(\psi_{s c c}\right)$,

14 which corresponds to the slab edge for these setup configurations. The same definition will be 15 used for the presentation of the test results of the experimental campaign.

16 The numerical model of setup (c) is similar to the numerical model established to simulate 17 an internal slab-column connection of the prototype building (Fig. 7a). The only differences 18 lie in the boundary conditions. For setup (c), the edges parallel to the $y$-axis were restrained 19 only against vertical displacement whereas the edges parallel to the $x$-axis were unrestrained. 20 The connection rotation for setup (c) and the continuous flat slab was computed as for setups 21 (b) and (b) mod.

(a) Continuous flat slab

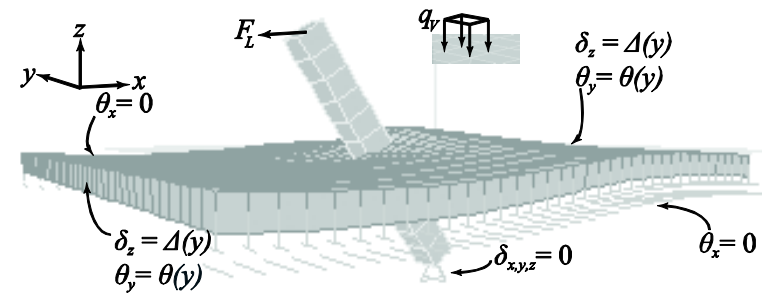

(b) Setup (b) $\bmod$

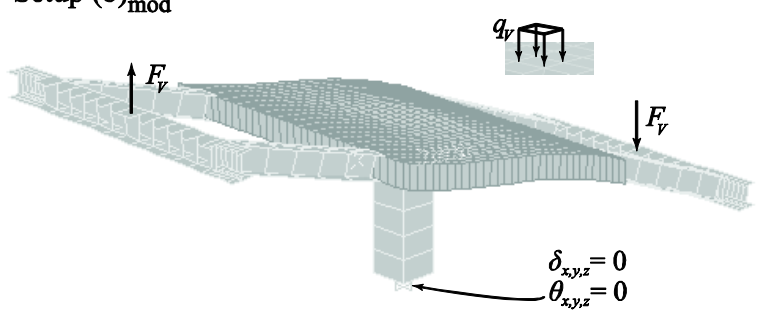


Fig. 7. Deformed shape of the established numerical models: (a) element $L \times L$ with continuity boundary conditions, and (b) setup (b) mod.

1

2 The influence of the adopted setup on the moment-rotation relationship of the slab-column 3 connection is shown in Fig. 8. Since punching failure is not captured by the numerical 4 analysis, the comparison should be based on the moment-rotation relationship up to the 5 moment capacity predictions according to ACI-318 [1] and Eurocode 2 [2] (dashed lines in 6 Figs. $8 \mathrm{a}$ and b). Modelling the slab only until $0.22 L$ (setup (b) and setup (b) mod) results in a 7 softer flexural behaviour than the continuous slab; this has already been demonstrated for the 8 case of vertical loads alone [28]. The difference in stiffness beween setup (b) and setup (b) $\bmod$ 9 results from the additional edge reinforcement that is provided in setup (b) mod. This effect is 10 smaller for larger reinforcement ratios (Fig. 8b) since the edge reinforcement was not scaled 11 with reinforcement content. Comparison between the continuous flat slab (Fig. 7a) and the 12 setup (c) shows that for the same specimen size $(1.0 L)$, the boundary conditions significantly 13 affect the moment-rotation response: The continuous flat slab is significantly stiffer than the 14 simply supported slab (setup (c)). Fig. 8 shows that for the two reinforcement ratios that were 15 investigated within the experimental campaign, setup (b) $)_{\bmod }$ yields from all investigated 16 setups the best estimate of the stiffness of the slab-column connection of the prototype 17 building. 

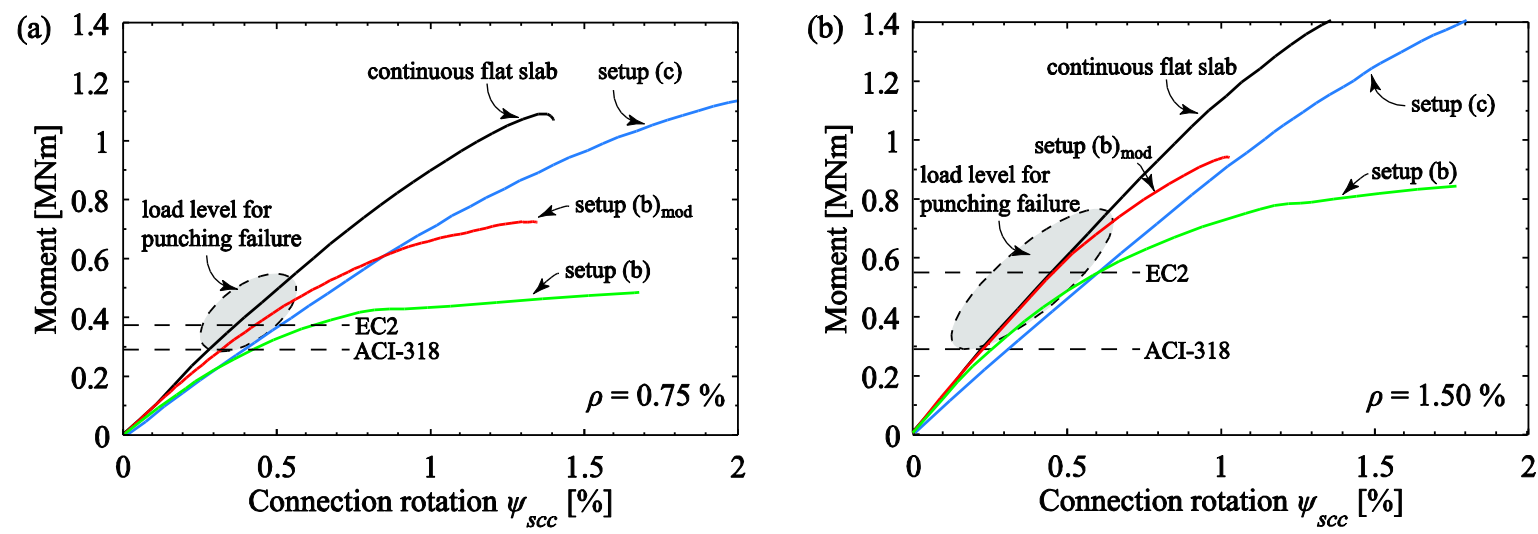

Fig. 8. Influence of the adopted setup on the estimation of the moment - rotation response of the continuous flat slab for flexural reinforcement ratio equal to: (a) $0.75 \%$, and (b) $1.50 \%$.

\section{Experimental campaign}

\subsection{Properties of test specimens}

Table 1 summarises the geometric and material properties as well as the value of the loading parameter. The dimensions of the 13 specimens were $3.0 \mathrm{~m} \times 3.0 \mathrm{~m}(B \times B)$ and the slab thickness was $250 \mathrm{~mm}$. The column size was equal to $390 \mathrm{~mm}$ x $390 \mathrm{~mm}(c \times c)$ for all tested slabs. Three different types of loading are distinguished: "V" stands for the application of symmetrical vertical loads, whereas " $\mathrm{M}$ " and " $\mathrm{C}$ " represent the introduction of monotonically and cyclically increasing unbalanced moments, respectively. The slab's top reinforcement $\rho$ consisted of $16 \mathrm{~mm}$ deformed bars per direction with $125 \mathrm{~mm}$ spacing for slabs with $0.75 \%$ nominal reinforcement ratio (Fig. 9a). For slabs with $1.50 \%$ nominal reinforcement ratio, 20 $\mathrm{mm}$ deformed bars were spaced at $100 \mathrm{~mm}$ in each direction. For the bottom mat, $10 \mathrm{~mm}$ and $14 \mathrm{~mm}$ deformed bars were spaced at $100 \mathrm{~mm}$ in each direction for slabs with $\rho^{\prime}=0.38 \%$ and $0.75 \%$ nominal bottom reinforcement ratio, respectively. The reinforcement layer with the biggest lever arm was positioned perpendicularly to the unbalanced moment vector for both top and bottom mat. The nominal effective depth, taken as the average value for both 
1 reinforcement directions until the rebar centre was $d=210 \mathrm{~mm}$. It was measured a posteriori

2 after saw cuts had been performed (see Table 1). The additional reinforcement in the slab

3 edges consisted of four threaded bars (diameter equal to $30 \mathrm{~mm}$ ) per edge with mean yield

4 stress $f_{y}$ and stress at failure $f_{u}$ equal to $754 \mathrm{MPa}$ and $847 \mathrm{MPa}$, respectively (average values

5 measured on $1.00 \mathrm{~m}$ bars). This reinforcement was also necessary to avoid the formation of

6 global mechanisms and to connect the slab to the steel frames for the moment application.

7 The nominal concrete cover was $20 \mathrm{~mm}$ for both top and bottom mat and the maximum

8 aggregate size $d_{g}$ was $16 \mathrm{~mm}$. The compressive strength of concrete $f_{c}$ (determined by

9 compression tests on concrete cylinders $160 \times 320 \mathrm{~mm}$ at the day of testing) and the mean

10 yield stress of reinforcing steel $f_{y}$ (average values measured on $0.90 \mathrm{~m}$ bars) are also reported

11 in Table 1. The fourth column gives the normalised shear force:

$$
v=V_{\text {test }} / b_{0} \cdot d \cdot \sqrt{f_{c}}
$$

12 where $b_{0}$ is the length of the control perimeter situated at a distance of $d / 2$ from the column

13 face, calculated with rounded corners [3]. It should be noted that the gravity shear ratio (GSR)

14 defined according to ACI-318 [1] is obtained when the normalised shear force $v$ according to

15 Eq. 3 (expressed in $\sqrt{\mathrm{MPa}}$ ) is multiplied by three (expressed in SI units). For tests PD7 and

16 PD9, which were subjected to increasing vertical loads alone ("V"), $V_{\text {test }}$ corresponds to the

17 maximum applied force which caused punching of the slab. For the other tests ("V+M",

18 "V+C"), $V_{\text {test }}$ was kept constant throughout the test and is the vertical load that was applied

19 before applying the seismic moment. The fifth column gives the ratio of the applied 20 normalised shear force $v$ to the normalised shear force $v_{r e f}$ of the reference slab ("V").

23 Table 1-Summary of properties of slab-column specimens tested by the authors (ordered by

24 loading type, $v$, and reinforcement ratio) 


\begin{tabular}{|l|l|c|c|c|c|c|c|c|c|c|c|}
\hline \multirow{2}{*}{$\begin{array}{l}\text { Loading } \\
\text { type }\end{array}$} & \multirow{3}{*}{ Slab } & \multicolumn{4}{|c|}{$\begin{array}{c}\text { Loading } \\
\text { parameter }\end{array}$} & \multicolumn{4}{c|}{$\begin{array}{c}\text { Material properties and } \\
\text { reinforcement }\end{array}$} & \multicolumn{2}{c|}{$\begin{array}{c}\text { Geometric } \\
\text { properties }\end{array}$} \\
\cline { 3 - 15 } & & $\begin{array}{c}V_{\text {test }}, \\
\mathrm{MN}\end{array}$ & $\begin{array}{c}v, \\
\sqrt{\mathrm{MPa}}\end{array}$ & $\begin{array}{c}v / v_{\text {ref }}, \\
-\end{array}$ & $\begin{array}{c}f_{c}, \\
\mathrm{MPa}\end{array}$ & $\begin{array}{c}d_{g}, \\
\mathrm{~mm}\end{array}$ & $\begin{array}{c}f_{y}, \\
\mathrm{MPa}\end{array}$ & $\begin{array}{c}\rho, \\
\%\end{array}$ & $\begin{array}{c}\rho^{\prime}, \\
\%\end{array}$ & $\begin{array}{c}d, \\
\mathrm{~mm}\end{array}$ & $\begin{array}{c}B, \\
\mathrm{~m}\end{array}$ \\
\hline $\mathrm{V}$ & PD7 & 0.983 & 0.359 & 1.00 & 39.2 & 16.0 & 507 & 0.80 & 0.35 & 200 & 3.00 \\
\hline $\mathrm{V}$ & PD9 & 1.040 & 0.419 & 1.00 & 34.3 & 16.0 & 593 & 1.61 & 0.74 & 195 & 3.00 \\
\hline $\mathrm{V}+\mathrm{M}$ & PD1 & 0.253 & 0.092 & 0.26 & 37.9 & 16.0 & 559 & 0.79 & 0.35 & 204 & 3.00 \\
\hline $\mathrm{V}+\mathrm{M}$ & PD4 & 0.376 & 0.137 & 0.38 & 39.0 & 16.0 & 507 & 0.80 & 0.35 & 201 & 3.00 \\
\hline $\mathrm{V}+\mathrm{M}$ & PD5 & 0.517 & 0.195 & 0.54 & 37.5 & 16.0 & 507 & 0.81 & 0.35 & 198 & 3.00 \\
\hline $\mathrm{V}+\mathrm{M}$ & PD3 & 0.734 & 0.288 & 0.80 & 34.9 & 16.0 & 558 & 0.81 & 0.34 & 198 & 3.00 \\
\hline $\mathrm{V}+\mathrm{M}$ & PD12 & 0.517 & 0.205 & 0.49 & 35.5 & 16.0 & 546 & 1.61 & 0.72 & 195 & 3.00 \\
\hline $\mathrm{V}+\mathrm{M}$ & PD10 & 0.734 & 0.301 & 0.72 & 32.3 & 16.0 & 593 & 1.60 & 0.72 & 197 & 3.00 \\
\hline $\mathrm{V}+\mathrm{C}$ & PD8 & 0.376 & 0.152 & 0.42 & 32.7 & 16.0 & 575 & 0.81 & 0.29 & 198 & 3.00 \\
\hline $\mathrm{V}+\mathrm{C}$ & PD6 & 0.517 & 0.192 & 0.53 & 38.3 & 16.0 & 507 & 0.81 & 0.30 & 199 & 3.00 \\
\hline $\mathrm{V}+\mathrm{C}$ & PD2 & 0.734 & 0.288 & 0.80 & 36.9 & 16.0 & 558 & 0.81 & 0.34 & 198 & 3.00 \\
\hline $\mathrm{V}+\mathrm{C}$ & PD13 & 0.517 & 0.201 & 0.48 & 36.5 & 16.0 & 546 & 1.61 & 0.72 & 196 & 3.00 \\
\hline $\mathrm{V}+\mathrm{C}$ & PD11 & 0.734 & 0.299 & 0.71 & 33.1 & 16.0 & 593 & 1.60 & 0.71 & 196 & 3.00 \\
\hline
\end{tabular}

(a)

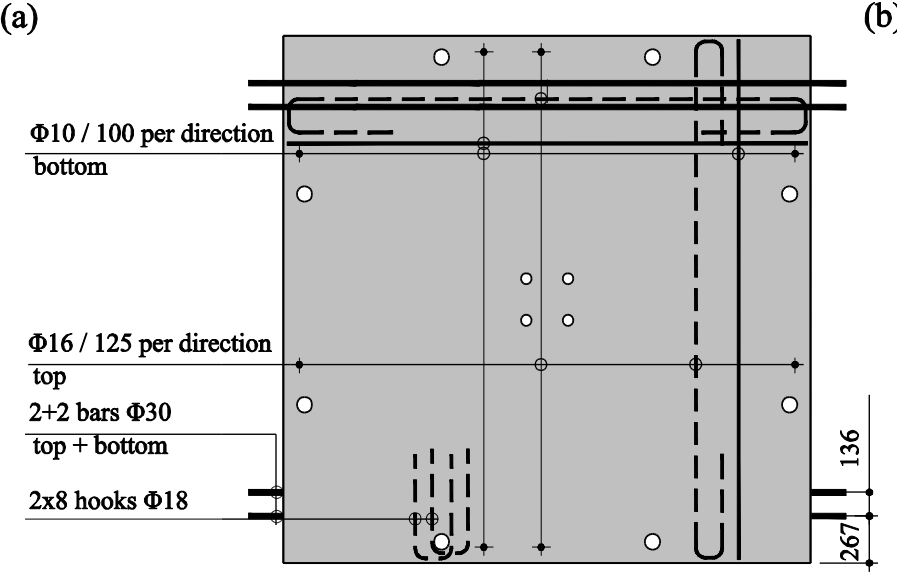

(b)

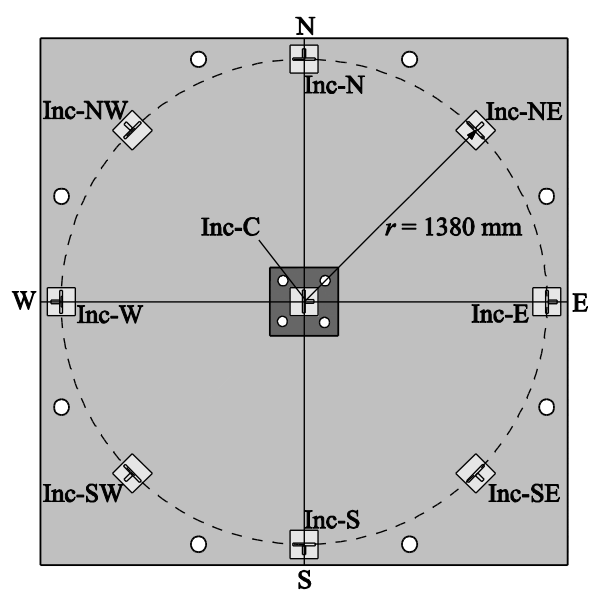

(c)

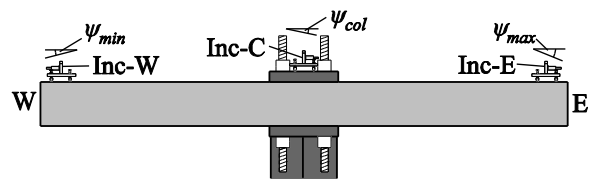

Fig. 9. (a) Reinforcement plan for slabs with $\rho=0.75 \%$ (dimensions in $\mathrm{mm}$ ), (b) position of inclinometers for measuring slab rotations and middle steel plate rotation, and (c) elevation view of the inclinometers monitoring the cyclic tests. 
2 The bottom face of all specimens was instrumented with 26 displacement transducers and

316 strain gauges to measure slab deflections and concrete strains along the axis perpendicular

4 to the moment vector direction (EW direction - see Fig. 9b). On the top face, nine

5 inclinometers recorded slab rotations in different directions (Fig. 9b). One of these

6 inclinometers was positioned on the middle of the specimen to measure the rotation of the

7 slab due to column deformation and a possible slab-column separation. The inclinometers that

8 were monitoring the quasi-static cyclic tests are shown in Figure 9c. In addition, strain gauges

9 were attached on selected rebars of the top and bottom mat in the EW direction to measure

10 strains at various locations. Since the present article focuses on the global response, only the

11 results of the inclinometers are used in the following.

\subsection{Loading procedure}

13 After the zero measurements, the vertical load was applied with a velocity of $20 \mathrm{kN} / \mathrm{min}$ at 14 eight points arranged on a radius of $1.504 \mathrm{~m}(=0.22 L)$. The slab was charged by means of 15 four hydraulic jacks, which applied each the same load on two points on the slab (Fig. 3). The 16 unbalanced moment was introduced by the two servo-controlled hydraulic actuators, of which 17 the master actuator was displacement-controlled and the other force-controlled. For the 18 specimens subjected to constant vertical load and monotonically increasing moment $(\mathrm{V}+\mathrm{M}-$

19 Table 1), the master actuator imposed a monotonically increasing downward displacement with a velocity of $0.2 \mathrm{~mm} / \mathrm{sec}$ until failure. The other actuator was imposing an upward 21 displacement and was force-controlled applying the same force amplitude as the master actuator but in opposite direction. In this way, a force couple was introduced to the slab-

23 column connection and the connection rotation was monotonically increasing. For the 24 specimens subjected to a constant vertical load and a cyclic moment $(\mathrm{V}+\mathrm{C}-\mathrm{Table} 1)$, the 25 displacement-controlled and force-controlled actuators were alternated at each half cycle with 
1 the same displacement velocity of the master actuator as for monotonic tests. The actuator

2 applying the downward force was always the displacement-controlled master actuator. The

3 control parameter was the slab-column connection rotation, defined as the mean value of the

4 inclinometers west and east minus the value of the column rotation (measured using an

5 inclinometer on the top plate, Fig. 9b). Two cycles were applied per rotation level. Since a

6 minimum number of eight cycles before failure were desired, a different loading protocol was

7 followed for tests with increased deformation capacity (Fig. 10a) and limited deformation 8 capacity (Fig. 10b). Throughout the moment application, the vertical load was manually

9 controlled to remain constant.

10
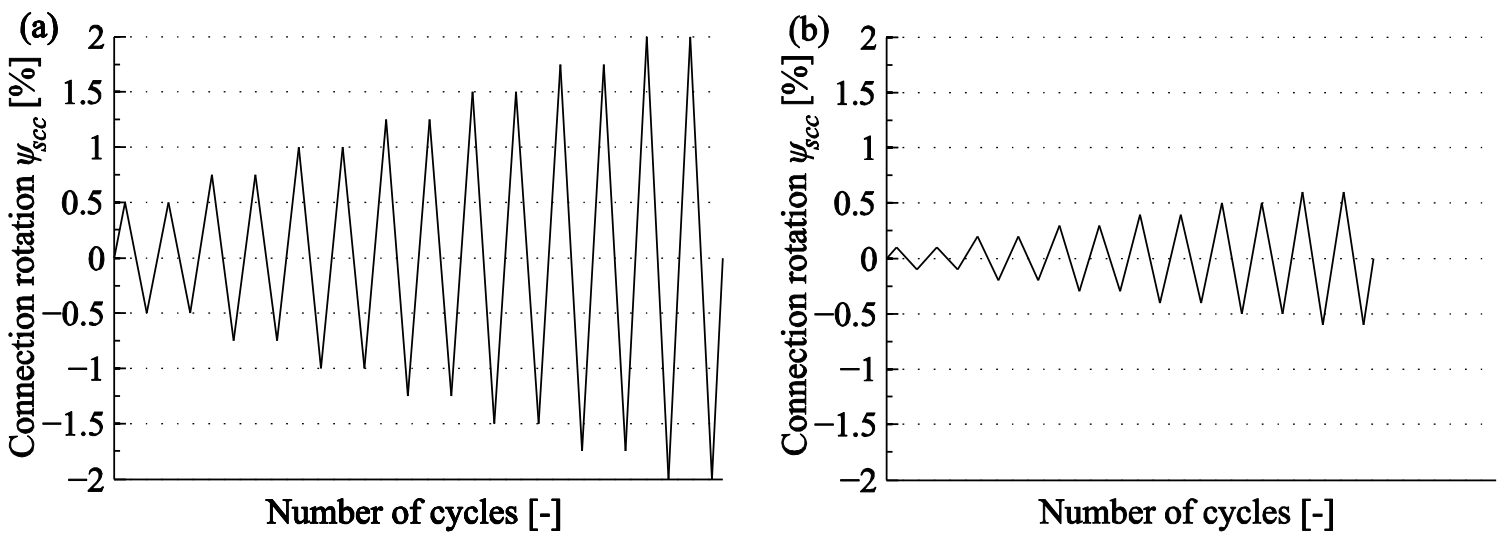

Fig. 10. Displacement history applied for cyclic testing of specimens with (a) increased deformation capacity (PD6, PD8 and PD13), and (b) limited deformation capacity (PD2 and PD11).

\subsection{Results}

13 The normalised vertical load-slab rotation curves for the reference tests PD7 and PD9

14 (without unbalanced moments) are shown in Fig. 11. Rotation $\psi_{v}$ is the average of rotation measurements on the east and west side of the slab. Fig. 11 shows also the vertical load levels applied to those slabs that were also subjected to an unbalanced moment. 


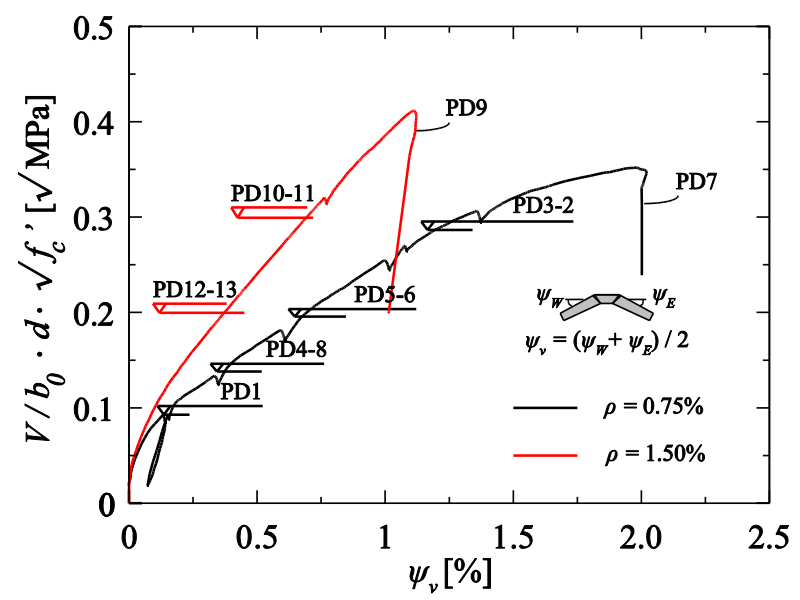

Fig. 11. Vertical load levels of tested slab specimens with respect to reference tests (concentric punching).

Table 2 summarises for the slabs that were subjected to a vertical load and an unbalanced

3 moment the obtained moment and slab-column connection rotation at peak load $\left(M_{\max }\right.$ and $4 \psi_{\text {scc.max }}$, respectively), at loss of vertical load bearing capacity, referred to as ultimate $\left(M_{u}\right.$ and $\psi_{s c c . u}$, respectively), as well as at $20 \%$ drop of unbalanced moment strength $\left(M_{80 \%}\right.$ and $\psi_{s c c .80 \%}$,

6 respectively) for slabs with $M_{80 \%}$ higher than $M_{u}$.

8 Table 2-Summary of results of tests on slab-column specimens subjected to combined

9 vertical load and moment

\begin{tabular}{|c|c|c|c|c|c|c|c|}
\hline \multirow[t]{2}{*}{ Slab } & \multirow[t]{2}{*}{$\begin{array}{l}\text { Loading } \\
\text { type }\end{array}$} & \multicolumn{3}{|c|}{ Moment, kNm } & \multicolumn{3}{|c|}{$\begin{array}{c}\text { Slab-column connection rotation, } \\
\%\end{array}$} \\
\hline & & $M_{\max }$ & $M_{80 \%}$ & $M_{u}$ & $\psi_{\text {scc.max }}$ & $\psi_{\text {scc. } 80 \%}$ & $\psi_{s c c . u}$ \\
\hline PD1 & $\mathrm{V}+\mathrm{M}$ & 525 & - & 503 & * & - & $*$ \\
\hline PD3 & $\mathrm{V}+\mathrm{M}$ & 200 & - & 177 & 0.45 & - & 0.60 \\
\hline PD4 & $\mathrm{V}+\mathrm{M}$ & 527 & - & 458 & 2.01 & - & 2.44 \\
\hline PD5 & $\mathrm{V}+\mathrm{M}$ & 462 & - & 435 & 2.19 & - & 2.39 \\
\hline PD10 & $\mathrm{V}+\mathrm{M}$ & 290 & - & 285 & 0.49 & - & 0.52 \\
\hline PD12 & $\mathrm{V}+\mathrm{M}$ & 469 & - & 461 & 1.21 & - & 1.27 \\
\hline PD2 & $\mathrm{V}+\mathrm{C}$ & 196 & 157 & 124 & 0.36 & 0.37 & 0.42 \\
\hline PD6 & $\mathrm{V}+\mathrm{C}$ & 372 & 297 & 287 & 0.86 & 0.84 & 0.84 \\
\hline
\end{tabular}




\begin{tabular}{|l|r|r|r|r|r|r|r|}
\hline PD8 & V+C & 384 & 307 & 307 & 1.30 & 1.66 & 1.66 \\
\hline PD11 & V+C & 286 & - & 231 & 0.43 & - & 0.50 \\
\hline PD13 & V+C & 410 & - & 345 & 0.86 & - & 0.88 \\
\hline
\end{tabular}

2

3 tests in terms of normalised moment resistance $\left(M_{\max } / b_{0} \cdot d^{2} \cdot \sqrt{f_{c}},[\sqrt{\mathrm{MPa}}]\right)$ and corresponding

4 slab-column connection rotation $\left(\psi_{\text {scc.max }}-\right.$ Table 2$)$.

5

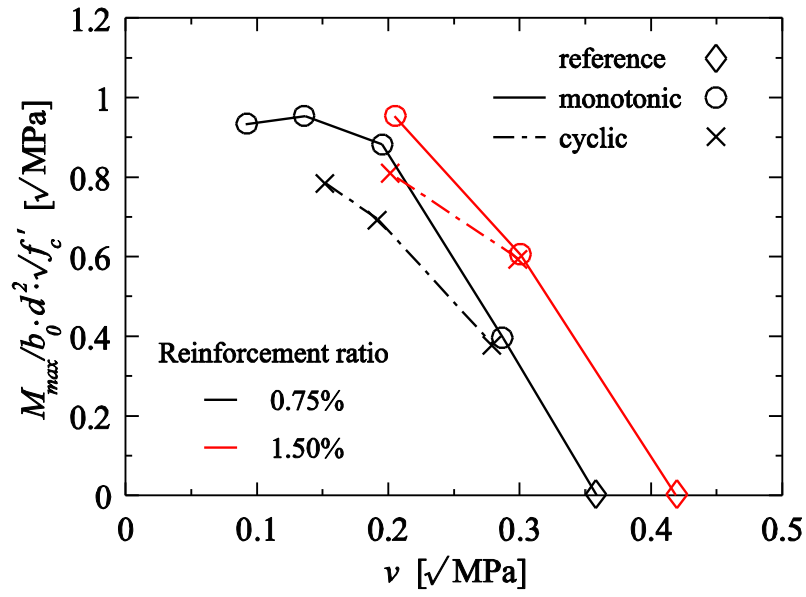

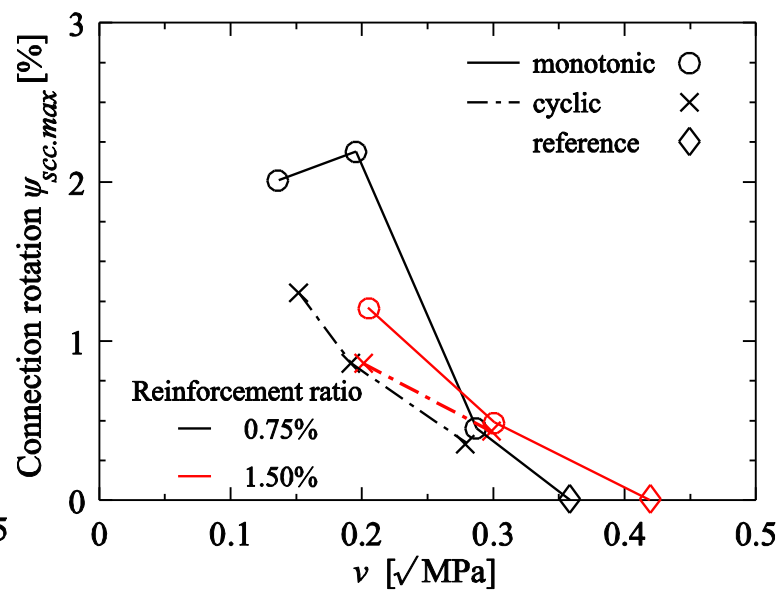

6 Fig. 12. Interaction diagrams resulting from the performed tests: (a) Moment capacity, and (b)

7 corresponding connection rotation.

8 The measured relationships between the introduced moment, slab-column connection

9 rotation and maximum and minimum local slab rotations for the slabs tested to investigate the

10 influence of gravity load and reinforcement ratio are shown in Fig. 13. A discussion of these

11 effects follows in Section 3.5. 

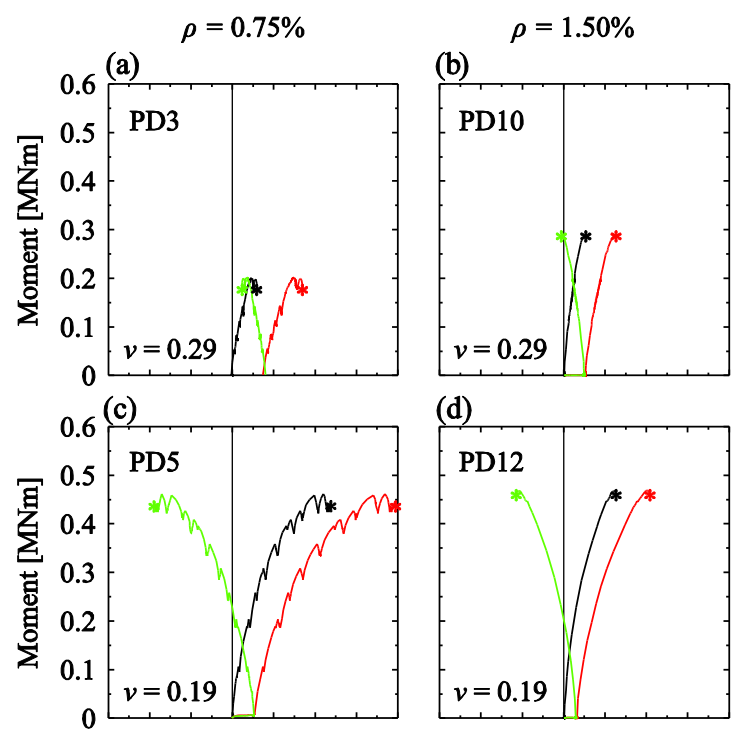

(d)
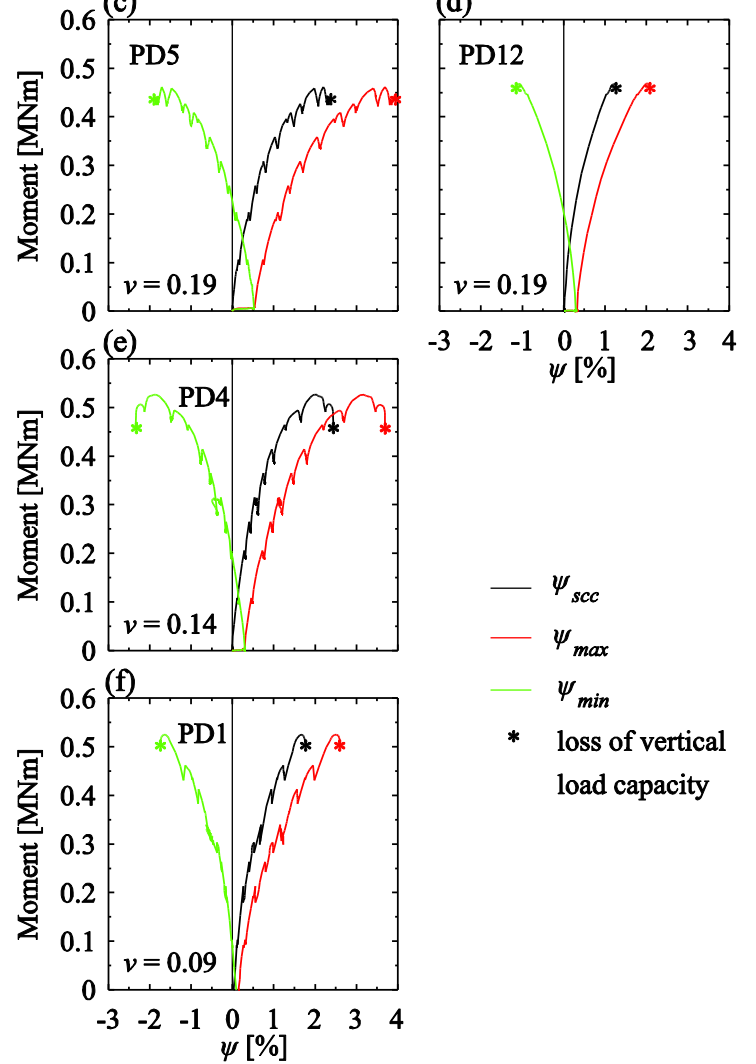

$$
\begin{array}{ll}
- & \psi_{s c c} \\
- & \psi_{\max } \\
- & \psi_{\min } \\
* & \text { loss of vertical } \\
& \text { load capacity }
\end{array}
$$

Fig. 13. Relationship between introduced moment, connection rotation and maximum and minimum local slab rotations for monotonic tests at different reinforcement ratios and vertical loads $(v[\sqrt{\mathrm{MPa}}]$ according to Eq. 3).

2 The comparisons of the moment-connection rotation response for the slabs tested to 3 investigate the cyclic loading effect are shown in Fig. 14 for all three vertical load levels that 4 were considered and for both flexural reinforcement ratios. 

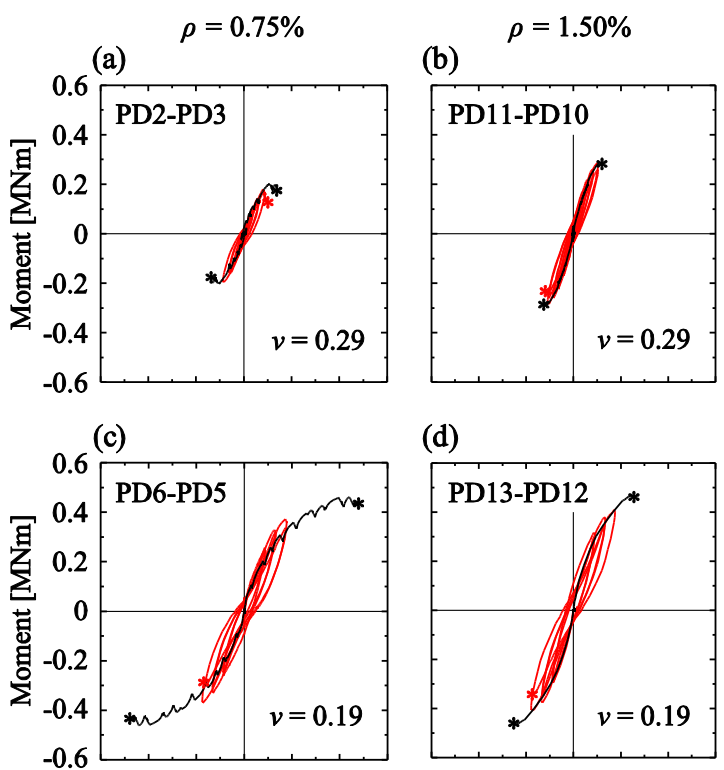

(d)
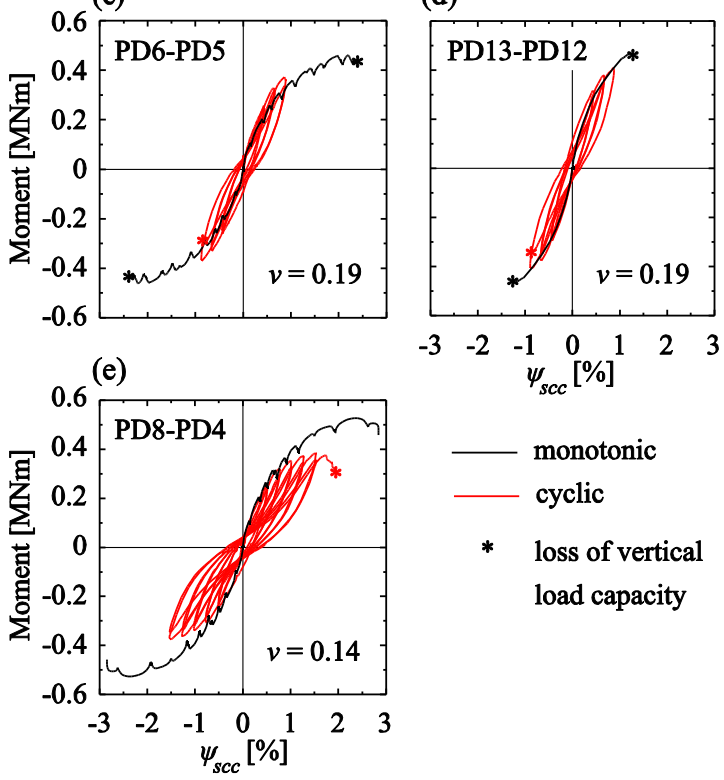

$$
\begin{array}{ll} 
& \text { monotonic } \\
& \text { cyclic } \\
* & \text { loss of vertical } \\
& \text { load capacity }
\end{array}
$$

Fig. 14. Moment -connection rotation

relationship for cyclic and monotonic tests at

different reinforcement ratios and vertical

loads ( $v[\sqrt{\mathrm{MPa}}]$ according to Eq. 3).

\section{1}

2

The cracking pattern of the top slab surface is illustrated in Figs. 15 and 16 for selected cases of slabs with $\rho=0.75 \%$ and $1.50 \%$ respectively. Cracks shown in black were drawn after the application of vertical loads. Cracks shown in red were caused by the unbalanced moment and were drawn after the end of each test. The slab half where the shear force due to the unbalanced moment acts downwards (i.e. in the direction of the vertical forces) is referred to as hogging slab half. The other slab half where the shear force due to unbalanced moment acts opposite to the shear force due to the vertical loads, is denoted as sagging slab half. In 
1 Figs. 15, 16, 17, 18 and 19, the hogging slab half is represented by positive $x$ values.

2 Moreover, since the $y$ axis $(x=0)$ is parallel to the vector of the applied moment, the $y$ axis

3 will be subsequently referred to as bending axis. All specimens failed due to punching of the

4 slab. For the reference specimens, which had been subjected to gravity loads only, the

5 punching was concentric; for the specimens subjected to combined gravity loads and

6 unbalanced moment, the punching-shear-related damage concentrated in the hogging slab

7 half. This concentration was naturally stronger for monotonic tests than for cyclic tests.

(a) PD4

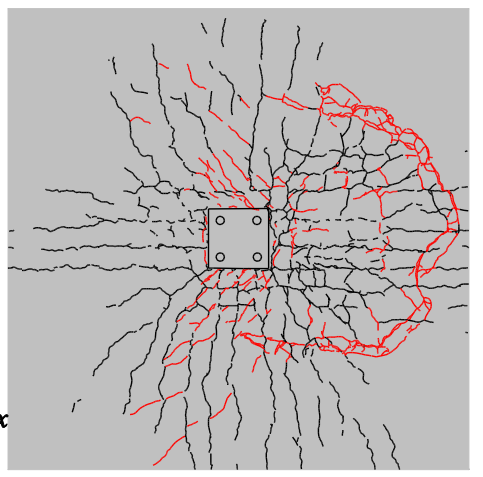

(a) PD9

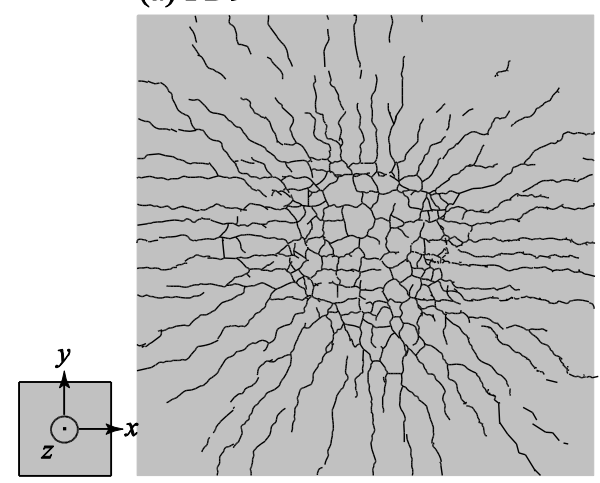

(b) PD8

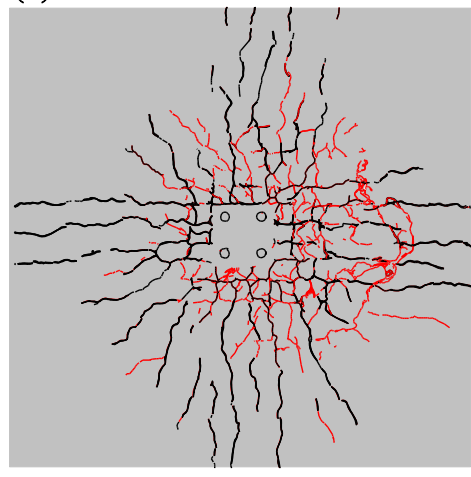

— vertical load _ moment (c) PD1

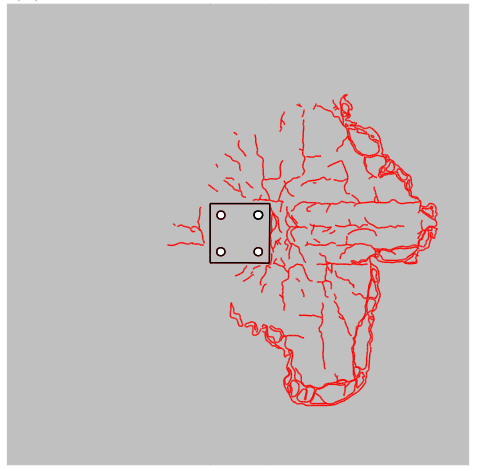

Fig. 15. Top surface cracking pattern for tested slabs with $0.75 \%$ flexural reinforcement ratio: (a) $v=0.14 \sqrt{\mathrm{MPa}}$ (monotonic loading), (b) $v=0.14 \sqrt{\mathrm{MPa}}$ (cyclic loading), and (c) $v=$ $0.09 \sqrt{\mathrm{MPa}}$ (monotonic loading).

(b) PD10

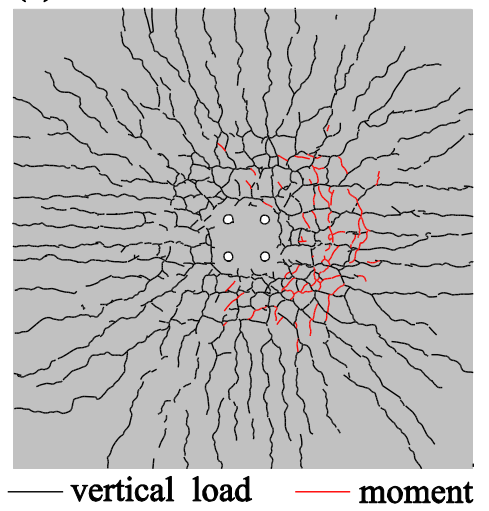

(c) PD12

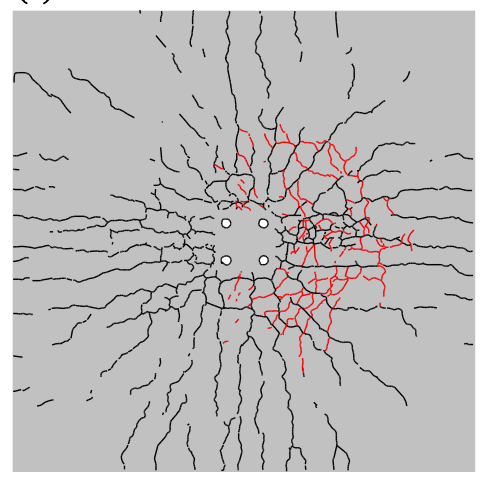


1 Fig. 16. Top surface cracking pattern for monotonically tested slabs with $1.50 \%$ flexural 2 reinforcement ratio: (a) reference slab $(v=0.42 \sqrt{\mathrm{MPa}})$, (b) $v=0.29 \sqrt{\mathrm{MPa}}$, and (c) $v=$ $30.19 \sqrt{\mathrm{MPa}}$.

4 To obtain information on the inclination of the shear crack at failure, saw cuts were 5 performed after each test. The saw cuts show the surface perpendicular to the unbalanced 6 moment vector (parallel to the $x$ direction). They illustrate the effect of the gravity load 7 (Fig.17), the loading history (Fig. 18) and the reinforcement ratio (Fig. 19) on the crack angle.

8 Note that PD11 $(\rho=1.50 \%-v=0.29 \sqrt{\mathrm{MPa}})$ was reloaded after a first drop in moment,

9 which resulted in complete punching of the slab and provoked additional cracks over the slab 10 thickness. These cracks are shown with grey colour in Figs. 17, 18, and 19.
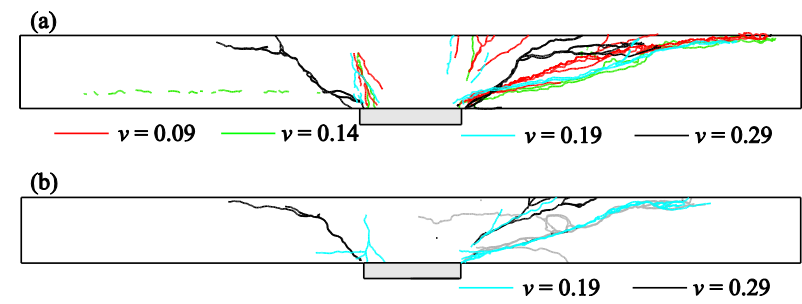

Fig. 17. Saw cut comparison for slabs tested under monotonically increasing moments to investigate the gravity load effect, with: (a) $0.75 \%$, and (b) $1.50 \%$ reinforcement ratio.

11
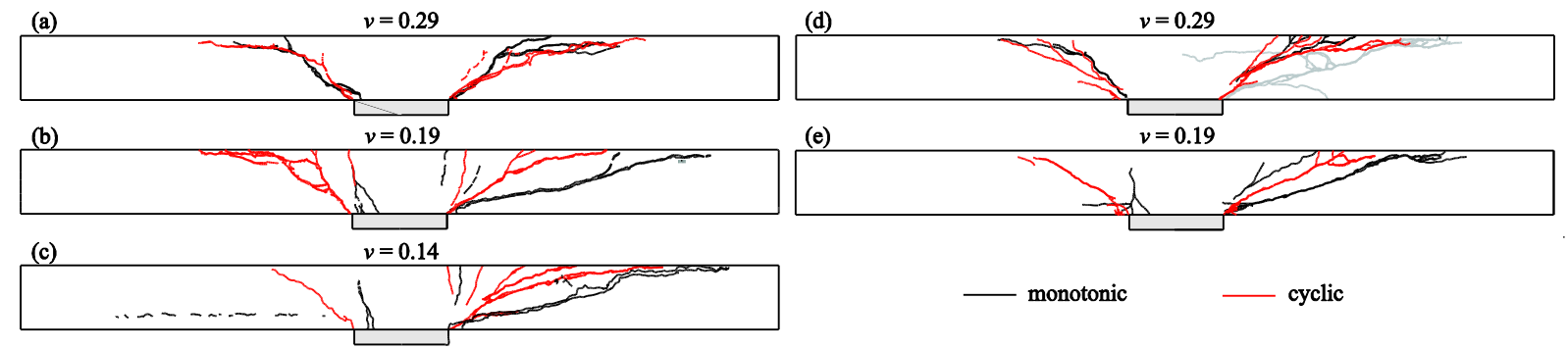

Fig. 18. Saw cut comparison for slabs tested under monotonically and cyclically increasing moments: (a) $\rho=0.75 \%-v=0.29$, (b) $\rho=0.75 \%-v=0.19$, (c) $\rho=0.75 \%-v=0.14$, (d) $\rho=$ 
$1.50 \%-v=0.29$, and (e) $\rho=1.50 \%-v=0.19$.

1
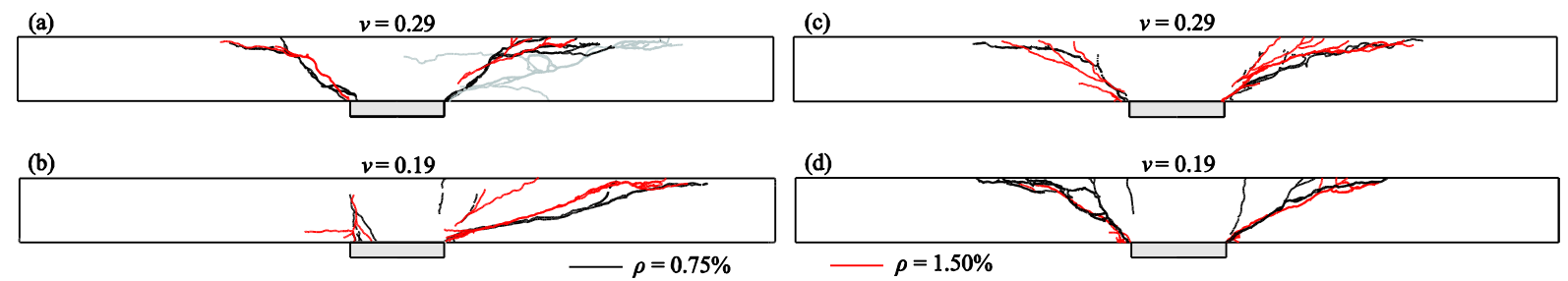

Fig. 19. Saw cut comparison for slabs with $0.75 \%$ and $1.50 \%$ reinforcement ratio under $v[\sqrt{\mathrm{MPa}}]$ equal to (a) 0.29 (monotonic loading), (b) 0.19 (monotonic loading), (c) 0.29 (cyclic loading), and (d) 0.19 (cyclic loading).

2

7

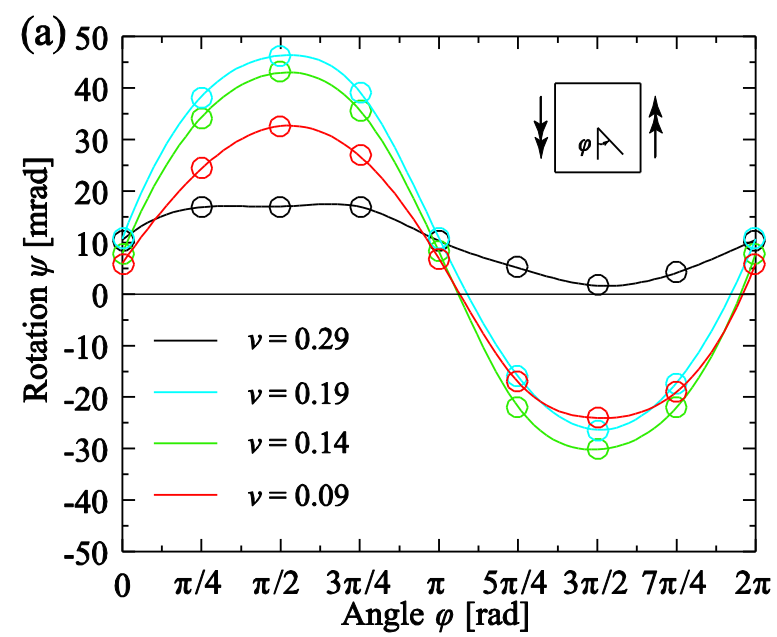

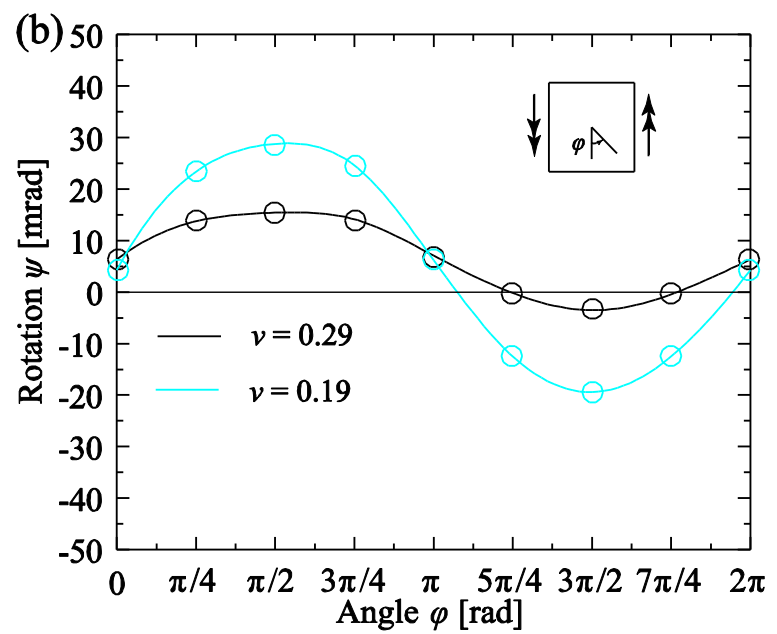

8 Fig. 20. Measured slab rotations at peak moment at varying angles from the bending axis $(\varphi=$

90 and $\varphi=\pi$ ) for slabs with: (a) $0.75 \%$ reinforcement ratio, and (b) $1.50 \%$ reinforcement ratio.

\subsection{Discussion}

11 The discussion focuses on the influence of three factors on the seismic behaviour of slab-

12 column connections, i.e., the influence of gravity loads, reinforcement ratio and loading 
1 history (monotonic vs cyclic). The first two factors are discussed with regard to the monotonic

2 test results (Sections 3.5.1 and 3.5.2). In the third section (Section 3.5.3), cyclic and

3 monotonic test results are compared. For each factor the effect of the initial stiffness, the peak

4 moment, the rotation capacity and the cracking pattern is discussed. The initial stiffness is

5 defined as the secant stiffness up to $75 \%$ of the peak moment and the rotation capacity as the

6 rotation at peak moment since punching failure occurs typically shortly after reaching the

7 peak moment.

\section{$8 \quad 3.5 .1 \quad$ Gravity load effect}

9 The effect of the gravity load on the stiffness, strength and deformation capacity of slab-

10 column connections without shear reinforcement has been extensively investigated by [4, 13,

$1124,22]$. The results of the present campaign are shown in Fig. 21 and largely confirm

12 previously observed trends. They provide, however, a more differentiated view with regard to

13 the gravity load effect on the rotation capacity (see discussion below).

14
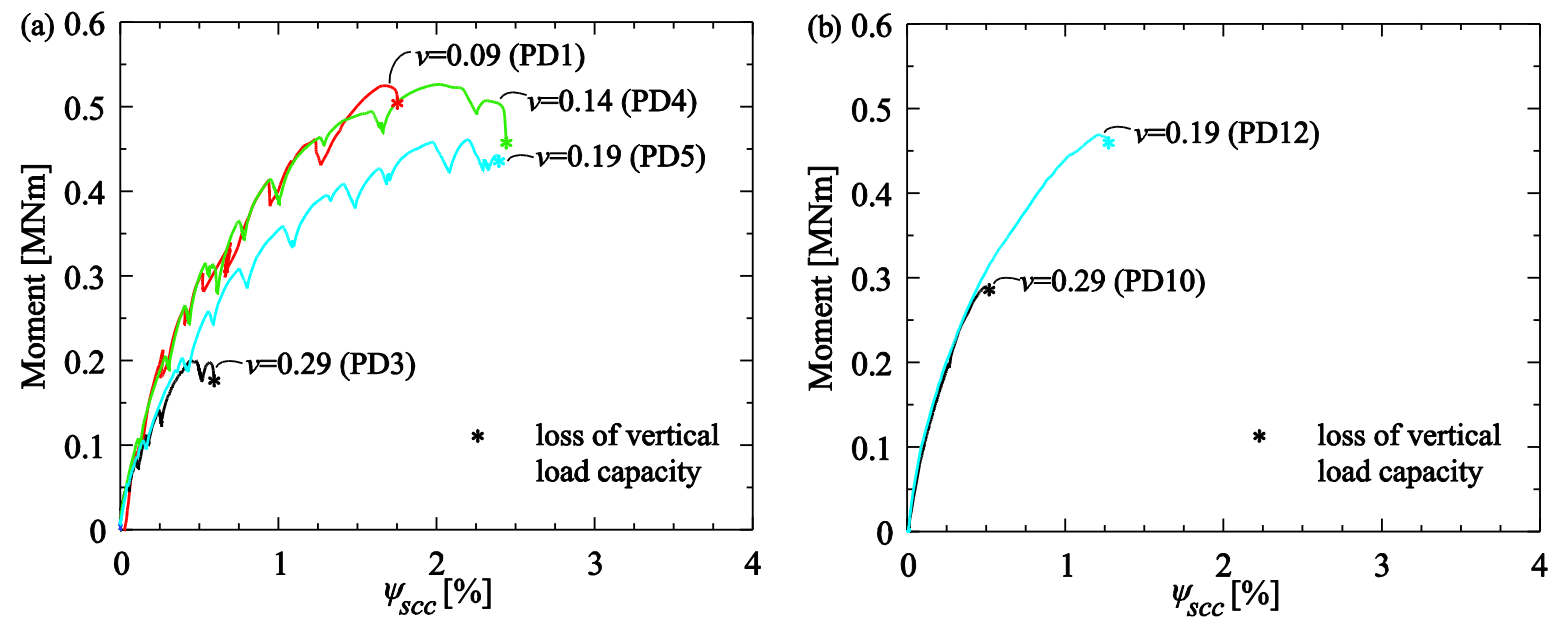

15 Fig. 21. Influence of vertical load on moment- slab-column connection rotation response, for:

(a) $\rho=0.75 \%$, and (b) $\rho=1.50 \%$. 
The test campaign comprised slabs subjected to normalised shear forces $v$ equal to 0.09 ,

$20.14,0.19$ and $0.29 \sqrt{\mathrm{MPa}}$. Fig. 21a shows that an increase in vertical loads results in a

3 decrease of the connection stiffness. The sensitivity of the stiffness is largest when increasing

$4 v$ from 0.14 to $0.19 \sqrt{\mathrm{MPa}}$, while it is rather small for $v<0.14 \sqrt{\mathrm{MPa}}$ and $v>0.19 \sqrt{\mathrm{MPa}}$ (Fig.

$5 \quad 21 \mathrm{a}$ and $\mathrm{b})$.

$6 \quad$ Moment capacity

7 The effect of vertical loads on the moment capacity of a slab-column connection depended 8 on the vertical load level (Fig. 12a and 21). In general, decreasing the vertical load, increased

9 the peak moment. Similar trends have been shown by previous studies [4, 13, 24]. This study

10 showed that the trend was stronger for slabs with $v \geq 0.19 \sqrt{\mathrm{MPa}}$ and less strong for $v<$

$110.19 \sqrt{\mathrm{MPa}}$. A gravity load of $0.19 \sqrt{\mathrm{MPa}}$ corresponds to half the punching shear strength

12 without unbalanced moment.

13 Rotation at peak moment

14 It is generally assumed that the rotation at peak moment decreases with increasing vertical 15 load (e.g. ACI-318 [1] and Pan and Moehle [4]). This experimental campaign confirmed this 16 trend for $v>0.19 \sqrt{\mathrm{MPa}}$ (Fig. 21). For lower vertical loads, however, the rotation at peak 17 moment increased slightly with increasing vertical loads (Fig. 21a). This is attributed to the 18 fact that higher vertical loads lead to more cracks and therefore to a reduced stiffness, which 19 increases the deformation capacity since the moment capacity remained almost unchanged. In 20 fact, the same observation can be inferred from results of previous tests [13, 24, 22].

\section{Cracking pattern}

22 The cracking pattern of the top slab surface was strongly influenced by the vertical load 23 level: the larger the vertical load level, the more cracks due to vertical loads and the fewer 24 cracks due to the unbalanced moment. This applied for both reinforcement ratios (Figs. 15a, c 
1 and 16). Concrete spalling of the top slab surface was observed only for slabs with $\rho=0.75 \%$

2 (Fig. 15a, c).

3 The saw cuts of slabs subjected to monotonic loading showed that if the maximum

4 eccentricity $M_{\max } / V$ was lower than $c / 2+d(v=0.29 \sqrt{\mathrm{MPa}}$ in Fig. 17), the shear crack

5 inclination was approximately 45 degrees for both hogging and sagging slab half. For higher

6 maximum eccentricities $(v<0.29 \sqrt{\mathrm{MPa}}$ in Fig. 17) the shear crack of the hogging slab half

7 was flatter, whereas no significant cracking was observed over the thickness of the sagging

8 slab half.

\section{$9 \quad 3.5 .2$ Reinforcement ratio effect}

10 The influence of the flexural reinforcement ratio on the moment-rotation response of slab-

11 column connections without transverse reinforcement has been thoroughly investigated in 12 several experimental campaigns [9, 11, 13, 22]. This test campaign varied not only for one 13 reinforcement ratio the gravity load but for two $(\rho=0.75$ and $1.50 \%)$. It therefore allows to 14 investigate the sensitivity of the gravity load effect with regard to the reinforcement ratio (Fig. 22).
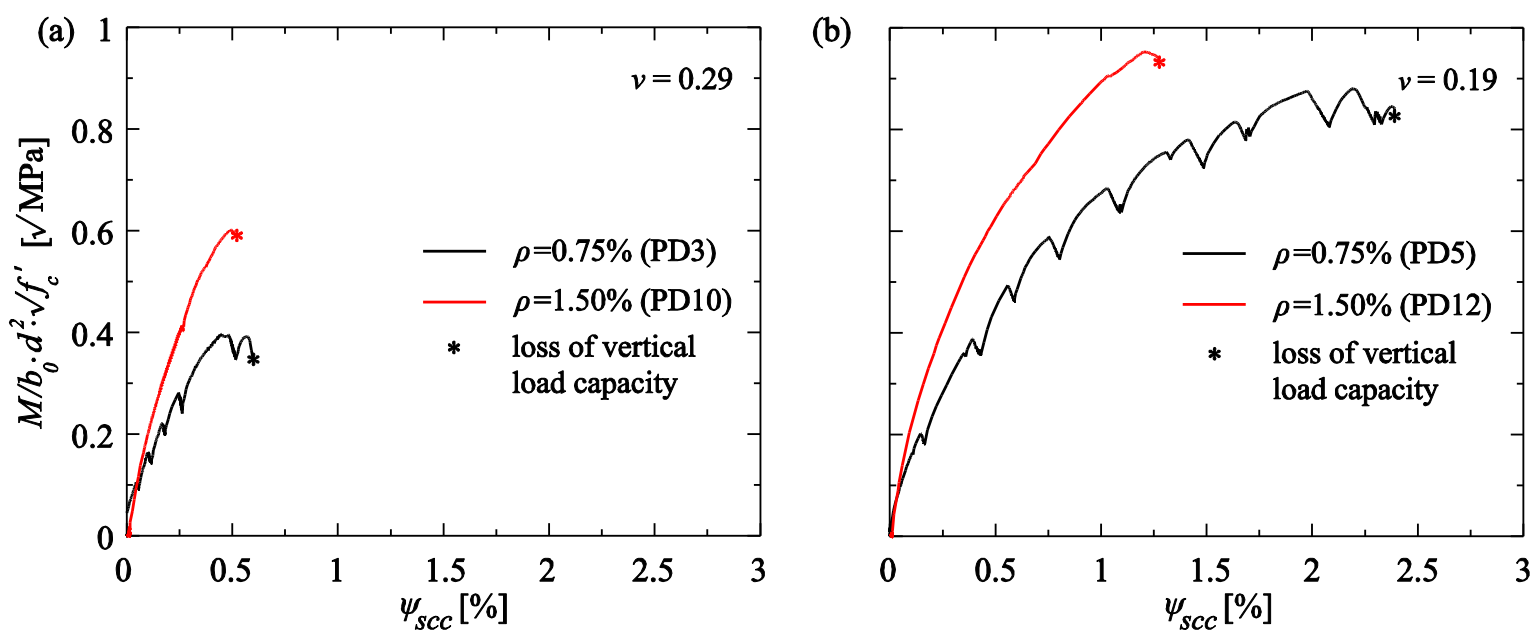

Fig. 22. Influence of reinforcement ratio on moment-rotation response for monotonically tested connections with $v$ equal to (a) $0.29 \sqrt{\mathrm{MPa}}$, and (b) $0.19 \sqrt{\mathrm{MPa}}$. 
2 Fig. 22 shows that doubling the flexural reinforcement ratio resulted in a significant

3 stiffness increase for both gravity load ratios.

\section{$4 \quad$ Moment capacity}

5 The effect of the flexural reinforcement ratio on the moment capacity depended on the 6 applied vertical load: For $v=0.29 \sqrt{\mathrm{MPa}}$ (Figs. 22a), doubling the reinforcement increased

7 significantly the peak moment; for lower vertical loads $(v=0.19 \sqrt{\mathrm{MPa}}$, Figs. 22b), doubling

8 the reinforcement ratio had almost no effect on the peak moment.

\section{$9 \quad$ Rotation at peak moment}

As for the moment capacity, the effect of the flexural reinforcement ratio on the deformation

11 capacity depended on the applied vertical load: For $v=0.29 \sqrt{\mathrm{MPa}}$, when increasing $\rho$ from $0.75 \%$ to $1.50 \%$ (Figs. 22a), the deformation capacity remained almost constant. For $v=$

The saw cuts showed that for high vertical loads $(v=0.29 \sqrt{\mathrm{MPa}})$ the shear crack inclination was not significantly affected by the reinforcement ratio (Fig. 19a). For lower vertical loads $(v=0.19 \sqrt{\mathrm{MPa}})$, an increase in the reinforcement ratio from $0.75 \%$ to $1.50 \%$ resulted in a slightly steeper shear crack in the hogging slab half (Fig. 19b).

\subsubsection{Cyclic loading effect}

21 Although existing experimental research on slab-column connections under both monotonically and cyclically increasing deformations is rather extensive, before this campaign only three pairs of specimens had been subjected to monotonic and cyclic moment to investigate the effect of the loading history. Out of these three pairs two investigated

25 isolated slab specimens [14, 20] and one a continuous flat slab [7]. These tests showed that 
1 cyclic loading had only a small effect on the moment strength. Deformation measurements are

2 only available for [20] and [7] and the effect of cyclic loading on the deformation capacity

3 was non-conclusive: For [7], the cyclic loading reduced the rotation capacity by more than a

4 factor of three but it had almost no effect for [20]. All three pairs investigated very thin slabs

$5 \quad(h=76-90 \mathrm{~mm})$. For such thin slabs, small variations in the thickness of the concrete cover

6 can have a large influence on the effective depth and therefore on the slab behaviour. The

7 present test campaign provides results for five pairs of slabs with $h=250 \mathrm{~mm}$ (Fig. 14),

8 which allows to investigate the influence of the loading history in more depth.

$9 \quad$ Stiffness

10 The initial stiffness of slabs tested under monotonically and cyclically increasing moments

11 were similar (Fig. 14a, b, d, e), small discrepancies being attributed to differences in the 12 material properties between monotonic and cyclic counterparts (Fig. 14c-Table 1).

Moment capacity

14 The moment capacity of cyclically loaded slabs was smaller than the moment capacity of 15 monotonically loaded slabs. This difference decreased for increasing gravity loads: - $\quad \rho=0.75 \%: v=0.14 \sqrt{\mathrm{MPa}}:-27 \%, v=0.19 \sqrt{\mathrm{MPa}}:-19 \%, v=0.29 \sqrt{\mathrm{MPa}}:-2 \%$

Rotation at peak moment

As for the moment capacity, the rotation capacity of cyclically loaded slabs is smaller than for monotonically loaded slabs. The difference varies between 12 and $61 \%$ :

For $v=0.19 \sqrt{\mathrm{MPa}}$ and $v=0.29 \sqrt{\mathrm{MPa}}$ the following trends can be observed: The larger the 24 gravity loads, the smaller the difference in rotation capacity between monotonic and cyclic tests. This is confirmed by measurements of the top reinforcement strain (Fig. 23). The 
1 difference is larger for $\rho=0.75 \%$ than for $\rho=1.50 \%$. For these tests, the envelope of the

2 moment-rotation curve of the cyclic test corresponded very well to the moment-rotation curve

3 of the monotonic test, with the difference that failure occurred earlier.

4
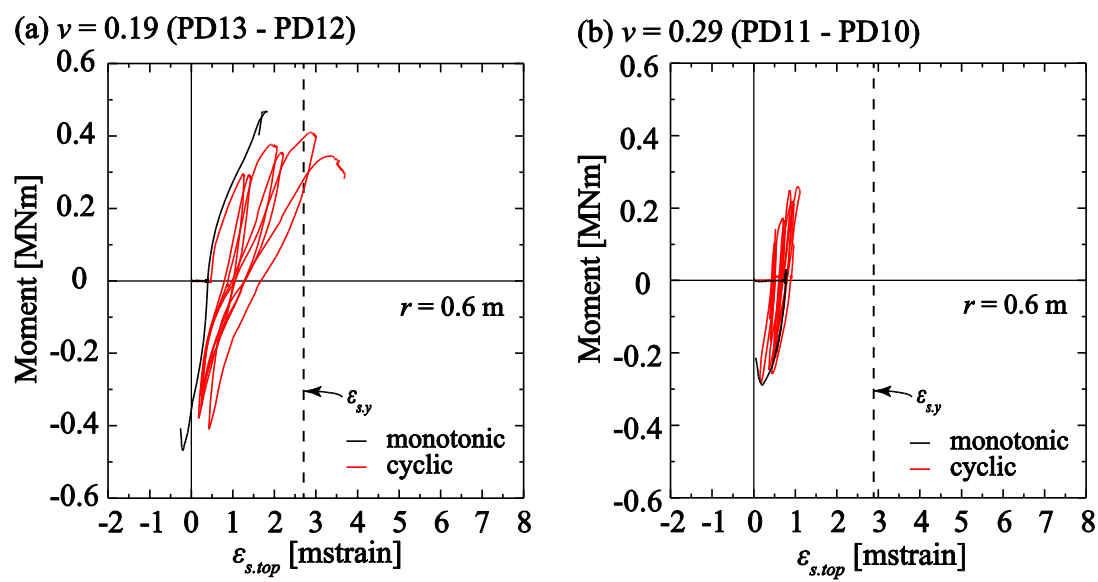

Fig. 23. Measured strains of the top reinforcing bars at a distance $r=0.6 \mathrm{~m}$ from the column axis for monotonically and cyclically tested slabs $(\rho=1.50 \%)$, for $v$ equal to (a) $0.19 \sqrt{\mathrm{MPa}}$, and (b) $0.29 \sqrt{\mathrm{MPa}}$.

6 When $v=0.14 \sqrt{\mathrm{MPa}}$ and $v=0.19 \sqrt{\mathrm{MPa}}$ are compared $(\rho=0.75 \%)$, the trend is different:

7 The monotonic rotation capacity is almost the same for both values of $v$ but the cyclic rotation

8 capacity is significantly larger for $v=0.14 \sqrt{\mathrm{MPa}}$ than for $v=0.19 \sqrt{\mathrm{MPa}}$. This is because for

$9 v=0.14 \sqrt{\mathrm{MPa}}$ the cyclically loaded specimen yields for $\mathrm{M}>0.80 M_{\max , c y c}$ a considerably

10 softer response than the monotonically loaded specimen.

11 Cracking pattern

12 The cyclic loading led naturally to a more symmetric cracking pattern than the monotonic 13 loading. This applies to the cracking pattern on the surface (Fig. 15) and saw cuts (Fig. 19).

14 Moreover, it was observed that for low vertical loads $(v \leq 0.19 \sqrt{\mathrm{MPa}})$, the shear crack at 15 failure was significantly steeper for cyclic tests than for their monotonic counterparts, both for 
$1 \rho=0.75 \%$ (Figs. 18b and c) and $1.50 \%$ (Fig. 18e). Steep shear cracks due to load reversals

2 indicate severe concrete degradation that limits the deformation capacity of the connection, as 3 has been observed by other researchers [33]. For higher vertical loads, the shear crack

4 inclination at failure was not significantly influenced by the loading type (Fig. 18a and d).

\section{4. Comparison to codes of practice}

In the following, the results of the tests are compared with the requirements of some codes of practice. The provisions for the design of slab-column connections in the presence of seismic moments according to ACI-318 [1], Eurocode 2 (EC2) [2] and fib-Model Code (MC2010) [3] are presented in annex. The performance of the aforementioned standards in predicting the peak moment and the corresponding connection rotation is assessed for the slabs tested in the present campaign. To this aim, mean strength values are used for both concrete and reinforcing steel and the partial factors $\gamma_{m}$ and $\varphi$ are set to unity. The resulting code predictions are shown in Table 3 in the form of ratio of predicted to observed values both for the maximum moment $M_{\max }$ and the corresponding slab-column connection rotation $\psi_{\text {scc.max }}$. As can be seen from Table 3, ACI-318 [1] and fib-Model Code (MC2010) [3] provide the most conservative predictions for the moment capacity of the tested slabs (ratio of predicted to observed values: $0.485 \pm 0.317$ and $0.478 \pm 0.294$, respectively), followed by EC2 [2] (0.723 \pm 0.200$)$.

Table 3- Ratios of predicted to experimental values of moment capacity $M_{\max }$ according to

21 ACI-318, EC2 and fib-MC2010 and corresponding connection rotation $\psi_{\text {scc.max }}$ according to

ACI-318 for the slabs tested under combined vertical load and moment

\begin{tabular}{|c|c|c|c|c|c|}
\hline Slab & $\begin{array}{c}\text { Loading } \\
\text { type }\end{array}$ & \multicolumn{3}{|c|}{$M_{\text {max.pred }} / M_{\text {max.exp }}[-]$} & $\begin{array}{c}\psi_{\text {scc.max.pred }} / \\
\psi_{\text {scc.max.exp }}[-]\end{array}$ \\
\cline { 3 - 6 } & & ACI-318 & EC2 & MC2010 & ACI-318 \\
\hline
\end{tabular}




\begin{tabular}{|l|r|r|r|r|r|}
\hline PD1 & $\mathrm{V}+\mathrm{M}$ & 0.710 & 0.903 & 0.655 & - \\
\hline PD3 & $\mathrm{V}+\mathrm{M}$ & 0.440 & 0.495 & - & - \\
\hline PD4 & $\mathrm{V}+\mathrm{M}$ & 0.581 & 0.721 & 0.464 & - \\
\hline PD5 & $\mathrm{V}+\mathrm{M}$ & 0.463 & 0.530 & 0.283 & - \\
\hline PD10 & $\mathrm{V}+\mathrm{M}$ & 0.231 & 0.721 & 0.362 & - \\
\hline PD12 & $\mathrm{V}+\mathrm{M}$ & 0.407 & 0.778 & 0.562 & 1.389 \\
\hline PD2 & $\mathrm{V}+\mathrm{C}$ & 0.515 & 0.561 & - & 0.721 \\
\hline PD6 & $\mathrm{V}+\mathrm{C}$ & 0.597 & 0.728 & 0.372 & 0.938 \\
\hline PD8 & $\mathrm{V}+\mathrm{C}$ & 0.659 & 0.857 & 0.565 & 1.163 \\
\hline PD11 & $\mathrm{V}+\mathrm{C}$ & 0.241 & 0.731 & 0.367 & 0.581 \\
\hline PD13 & $\mathrm{V}+\mathrm{C}$ & 0.488 & 0.924 & 0.668 & - \\
\hline $\begin{array}{l}\text { Mean } \pm \mathrm{CoV} \\
(\mathrm{all} \mathrm{tests})\end{array}$ & & $\mathbf{0 . 4 8 5} \pm \mathbf{0 . 3 1 7}$ & $\mathbf{0 . 7 2 3} \pm \mathbf{0 . 2 0 0}$ & $\mathbf{0 . 4 7 8} \pm \mathbf{0 . 2 9 4}$ & $\mathbf{0 . 9 5 8} \pm \mathbf{0 . 3 4 0}$ \\
\hline $\begin{array}{l}\text { Mean } \pm \mathrm{CoV} \\
(\mathrm{V}+\mathrm{M})\end{array}$ & & $\mathbf{0 . 4 7 2} \pm \mathbf{0 . 3 4 4}$ & $\mathbf{0 . 6 9 1} \pm \mathbf{0 . 2 2 3}$ & $\mathbf{0 . 4 6 5} \pm \mathbf{0 . 3 2 1}$ & $\mathbf{0 . 3 4}$ \\
\hline $\begin{array}{l}\text { Mean } \pm \mathrm{CoV} \\
(\mathrm{V}+\mathrm{C})\end{array}$ & & $\mathbf{0 . 5 0 0} \pm \mathbf{0 . 3 1 9}$ & $\mathbf{0 . 7 6 0} \pm \mathbf{0 . 1 8 3}$ & $\mathbf{0 . 4 9 3} \pm \mathbf{0 . 3 0 2}$ & $\mathbf{0 . 9 5 8} \pm \mathbf{0 . 3 4 0}$ \\
\hline
\end{tabular}

The normalised moment-shear force interaction diagrams according to ACI-318 [1], EC2 [2] and fib-MC2010 [3] are shown in Fig. 24a and b for nominal flexural reinforcement ratios equal to $0.75 \%$ and $1.50 \%$, respectively. Since discrepancies among the material properties and the effective depth $d$ of the tested slabs do not influence to a significant degree the code predictions, the curves are drawn for the average experimental values of $f_{c}, f_{y}$ and $d$ (see Table 1). The experimental results of the presented campaign are also shown (represented with markers). Fig. 24 shows that an increase of reinforcement ratio from $0.75 \%$ to $1.50 \%$ increases the conservatism of the predictions of ACI-318 [1]. The predictions of EC2 [2] and fib-MC2010 [3] are also conservative but appear to follow the experimental trend. 

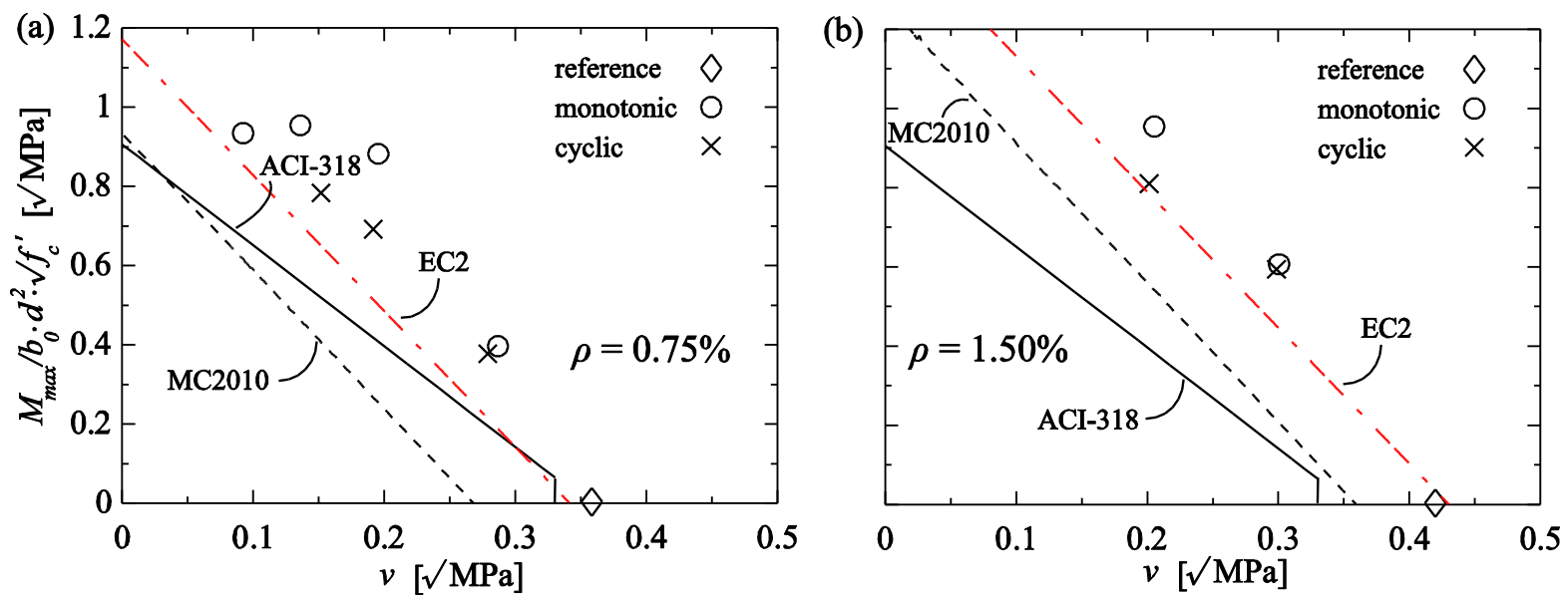

Fig. 24. Code predictions for the moment capacity of the tested slab specimens: (a) $\rho=$ $0.75 \%$, and (b) $\rho=1.50 \%$.

1

Only ACI-318 [1] provides a lower-bound limit for the deformation capacity of slab-column connections subjected to reversed cyclic loading in terms of interstorey drift. The drift limit of ACI-318 [1] along with the connection rotation at peak moment for the cyclic tests of the present campaign are shown in Fig. 25, as function of GSR (according to ACI-318 [1]) in the bottom abscissa, and $v$ (according to Eq. 3) in the top abscissa. In average, the deformation capacity is predicted rather well $(0.958 \pm 0.340)$. Assuming the contribution of column 8 deformations to interstorey drifts is small, ACI-318 [1] provides deformation capacity

estimates on the unsafe side for GSR $>0.60$ (corresponding to the shear ratio at the beginning 0 of the horizontal branch shown in Fig. 25). This has already been reported by other researchers [34]. 


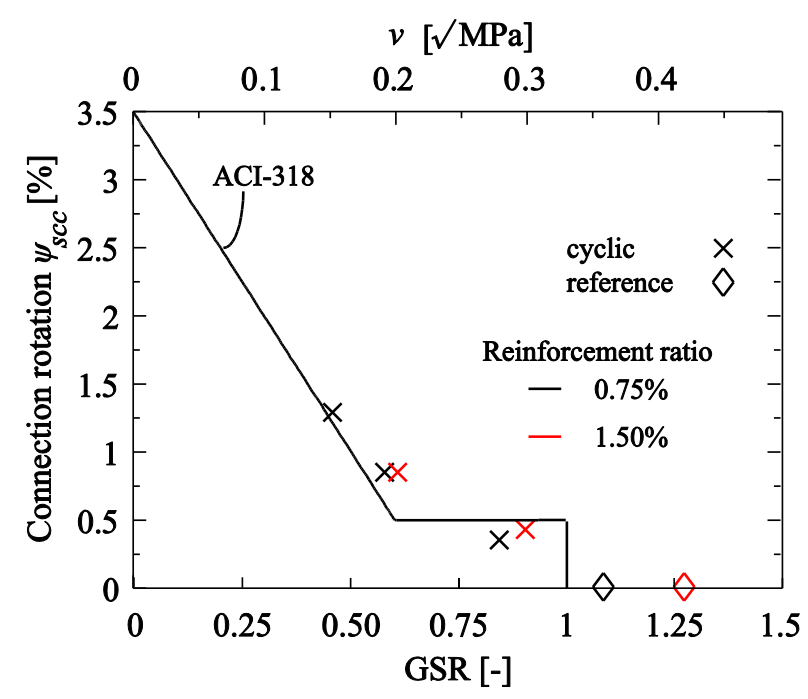

Fig. 25. Connection rotation at peak moment

for the cyclic tests of the present campaign and allowable drift limit according to ACI-318.

\section{Conclusions}

2

This article presents the results of an experimental campaign on the seismic behaviour of internal reinforced concrete slab-column connections without transverse reinforcement with main objective to investigate the effect of cyclic loading on the moment-rotation response. The campaign comprised 13 full-scale isolated slab-column specimens. The adopted setup configuration is presented and compared to setup configurations used in past experimental studies. The results were discussed with regard to the effect of gravity loads, reinforcement ratio and loading history (monotonic vs cyclic) on the stiffness, strength, deformation capacity and cracking pattern of the slab-column connection. The obtained experimental results were also compared to the predictions of ACI-318, Eurocode 2 (EC2) and fib-Model Code 2 (MC2010) for moment strength and deformation capacity. The main conclusions of this article are:

- Nonlinear finite element analyses showed that stiffness and deformation capacity of slab-column connections depend on the chosen experimental setup. The setup 
configuration adopted for the present study reproduces well the moment-connection rotation response of an internal slab-column connection of a typical building configuration.

- Reversed cyclic loading reduces the moment capacity and the deformation capacity of slab-column connections. This effect is more pronounced for smaller gravity loads and smaller reinforcement ratios. In general, the envelope of the cyclic response corresponded to the curve of the monotonic test, with the difference that failure occurred earlier for the cyclic test. However, for very low gravity loads, cyclic loading resulted in a softer moment-rotation response than for monotonic loading for moments higher than $80 \%$ of the peak cyclic moment.

- For slabs subjected to cyclically increasing moments, the shear crack at failure is steeper than for slabs subjected to monotonically increasing moments. This effect is more marked for smaller gravity loads than for larger gravity loads.

- Increasing gravity loads reduces the stiffness and the moment capacity of slab-column connections as observed by others. With regard to the deformation capacity a more differentiated trend was identified: For gravity loads larger than a threshold value, the deformation capacity decreases with increasing gravity load. For gravity loads smaller than this threshold value, however, the trend did not continue but smaller gravity loads led to a reduced deformation capacity. This was attributed to the smaller extend of cracking for small vertical loads. From the present experimental campaign this threshold value was found to correspond to approximately half the punching strength under concentric gravity loads $\left(V_{\text {test }} / b_{0} \cdot d \cdot \sqrt{f_{c}}=0.19 \sqrt{\mathrm{MPa}}\right)$. Note that such a change in trend was not observed for cyclic tests for which the deformation capacity always increased with decreasing gravity loads. 
- Increasing reinforcement content resulted in general in higher stiffness and lower deformation capacity, as has been noted by previous studies. For low gravity loads, increasing the reinforcement ratio had however little influence on the moment capacity. For high gravity loads, increasing the reinforcement ratio had little influence on the deformation capacity.

- ACI-318 and fib-MC2010 provide the most conservative estimates of the moment capacity, followed by EC2 with respect to both accuracy and precision.

- The allowable drift limit of ACI-318 estimates rather accurately the connection rotation capacity of the cyclic tests. However, ACI-318 appears to overestimate the rotation capacity for high vertical loads (GSR > 0.6).

\section{Acknowledgements}

The work presented in this article was supported by the Swiss National Science Foundation (Grant 143747). The opinions and conclusions in this paper are those of the authors, and do not necessarily represent those of the sponsors.

\section{References}

[1] Building Code Requirements for Structural Concrete, ACI 318-14. American Concrete Institute, ACI Committee 318, USA; 2014. 519 p.

[2] Eurocode 2: Design of concrete structures - Part 1-1: general rules and rules for buildings. European Committee for Standardization (CEN), Brussels, Belgium; 2004, $225 \mathrm{p}$.

[3] fib. fib-Model Code for Concrete Structures 2010; Ernst \& Sohn, Berlin, Germany; 2013. 434 p.

[4] Pan A, Moehle JP. Lateral displacement ductility of reinforced concrete flat plates. ACI Struct J 1989; (86)3: 250-258.

[5] Durrani AJ, Du Y, Luo YH. Seismic resistance of nonductile slab-column connections in existing flat-slab buildings. ACI Struct J 1995; (92)4: 479-487.

[6] Hwang SJ, Moehle JP. An experimental study of flat-plate structures under vertical and lateral loads. Report No. UCB/SEMM-90/11 1990; 279 p.

[7] Rha C, Kang THK, Shin M, Yoon JB. Gravity and lateral load-carrying capacities of reinforced concrete flat plate systems. ACI Struct J 2014; (111)4: 753-764. 
[8] Fick DR. Experimental investigation of a full-scale flat-plate reinforced concrete structure subjected to cyclic lateral loading in the inelastic range of response. Doctoral thesis, University of Purdue. West Lafayette - Indiana, U.S.A.; 2008, 188 p.

[9] Ghali A, Elmasri M, Dilger W. Punching of flat plates under static and dynamic horizontal forces. ACI J 1976; (73)10: 566-572.

[10] Elgabry AA, Ghali A. Tests on concrete slab-column connections with stud-shear reinforcement subjected to shear-moment transfer. ACI Struct J 1987; (87)4: 433-442.

[11] Hawkins NM, Bao A, Yamazaki J. Moment transfer from concrete slabs to columns. ACI Struct J 1989; (86)6: 705-716.

[12] Robertson IN, Kawai T, Lee J, Enomoto B. Cyclic testing of slab-column connections with shear reinforcement. ACI Struct J 2002; (99)5: 605-613.

[13] Robertson IN, Johnson G. Cyclic lateral loading of nonductile slab-column connections. ACI Struct J 2006; (103)3: 356-364.

[14] Hanson, NW, Hanson JM. Shear and moment transfer between concrete slabs and columns. Res Dev Bull PCA 1968: 2-16.

[15] Hawkins NM, Mitchell D, Sheu MS. Cyclic behaviour of six reinforced concrete slabcolumn specimens transferring moment and shear. NSF Progress report 1973-74; No. 6: $143 \mathrm{p}$.

[16] Elstner RC, Hognestad E. Shearing strength of reinforced concrete slabs. ACI Mat J 1956; (28)1: 29-58.

[17] Moe J. Shearing strength of reinforced concrete slabs and footings under concentrated loads. Res Dev Bull PCA 1961: 135 p.

[18] Krüger G. Eccentric punching resistance of flat slabs. Doctoral thesis, Ecole Polytechnique Fédérale de Lausanne. Lausanne, Switzerland; 1999, 191 p. (in French)

[19] Binici B, Bayrak O. Upgrading of slab-column connections using fiber reinforced polymers. Eng Struct 2005; (27)1: 97-107.

[20] Islam S, Park R. Tests on slab-column connections with shear and unbalanced flexure. J Struct Div 1976; (102)ST3: 549-568.

[21] Stark A, Binici B, Bayrak O. Seismic upgrade of reinforced concrete slab-column connections using carbon fiber-reinforced polymers. ACI Struct J 2005; (102)2: 324333.

[22] Choi MS, Cho IJ, Han BS, Ahn JM, Shin SW. Experimental study of interior slabcolumn connections subjected to vertical shear and cyclic moment transfer. Key Eng Mat 2007; (348-349): 641-644.

[23] Park JM, Han SW, Ryu JH. Comparison of seismic behaviors of interior joints in PT and RC flat plate systems. Key Eng Mat 2007; (348-349): 741-745.

[24] $\mathrm{Bu} \mathrm{W}$, Polak MA. Seismic retrofit of reinforced concrete slab-column connections using shear bolts. ACI Struct J 2009; (106)4: 514-522.

[25] Choi JW, Ali M, Alexander SDB. Behavior of slab-column connections with partially debonded reinforcement under lateral loading. Canadian J of Civil Eng 2009; (36)3: 463-472.

[26] Tian Y, Jirsa JO, Bayrak O, Widianto, Argudo JF. Behavior of slab-column connections of existing flat-plate structures. ACI Struct J 2008; (105)5: 561-569.

[27] Tian Y. Behavior and modeling of reinforced concrete slab-column connections. Doctoral thesis, The University of Texas at Austin. Austin, U.S.A.; 2008, 230 p. 
[28] Einpaul J, Fernández Ruiz M, Muttoni A. Influence of moment redistribution and compressive membrane action on punching strength of flat slabs. Eng Struct 2015; (86)1: 43-57.

[29] Park H, Choi K. Improved strength model for interior flat plate-column connections subject to unbalanced moment. J Struct Eng 2006; (132)5: 694-704.

[30] Computers and Structures, Inc. SAP200 V-17 (Trial version). Integrated finite element analysis and design of structures.

[31] Mander JB, Priestley MJN, Park R. Theoretical stress-strain model for confined concrete. J Struct Eng 1988; (114)8: 1804-1826.

[32] Park R, Paulay T. Reinforced Concrete Structures, John Wiley, New York; 1975.

[33] Matzke EM, Lequesne RD, Parra-Montesinos GJ, Shield CK. Behavior of biaxially loaded slab-column connections with shear studs. ACI Struct J 2015; (112)3: 335-346.

[34] Broms CE. Design method for imposed rotations of interior slab-column connections. ACI Struct J 2009; (106)5: 636-645.

[35] Choi K-K, Shin D-W, Park H-G. Shear-strength model for slab-column connections subjected to unbalanced moment. ACI Struct J 2014; (111)3: 491-502.

\section{ANNEX}

\section{ACI-318 provisions for moment transfer in slab-column connections}

It is assumed that a fraction of the unbalanced moment (equal to the coefficient $\gamma_{v}$ ) is resisted by the eccentric shear force mechanism. The shear stresses due to the unbalanced moment $M$ are superimposed to the shear stresses due to vertical loads $V$ :

$$
v_{E}=\frac{V}{b_{0, A C I} \cdot d} \pm \frac{\gamma_{v} \cdot M \cdot j_{d}}{J_{c}}
$$

where $b_{0, A C I}$ is the length of the control perimeter (located at a distance of $d / 2$ from the column face), $j_{d}$ is the distance between the centroid and edge of the critical perimeter, and $J_{c}$ is the polar moment of inertia of the critical perimeter.

The total maximum shear stress $v_{R}$ acting on the control perimeter is: 


$$
v_{R}=\min \left\{0.17 \cdot\left(1+\frac{2}{\beta_{c}}\right), 0.083 \cdot\left(2+\frac{\alpha_{s} \cdot d}{b_{0, A C I}}\right), \frac{1}{3}\right\} \cdot \sqrt{f_{c}}
$$

1

2 where $\beta_{c}$ is the ratio of long to short side of the column and $\alpha_{s}$ is a parameter equal for 40 for

3 interior slab-column connections, 30 for exterior slab-column connections, and 20 for corner

4 slab-column connections. The slabs tested in this program are controlled by the third term of 5 Eq. A.2.

6 According to ACI-318 the transferred moment cannot be larger than the moment resisted by 7 flexure by the hogging and sagging reinforcement $\left(m_{R, h o g}\right.$ and $m_{R, s a g}$, respectively) over a 8 width equal to $c+3 h$. The maximum unbalanced moment can therefore be calculated using the 9 following formula:

10

$$
M_{\max }=\min \left\{\frac{v_{R^{-}} \frac{V}{b_{0, A C l} \cdot d}}{\gamma_{v} \dot{j}_{d}} \cdot J_{c}, \frac{\left(m_{R, h o g}+m_{R, s a g}\right) \cdot(c+3 \cdot h)}{1-\gamma_{v}}\right\}
$$

11

12 ACI-318 [1] is the only code that imposes drift limitations for slab-column connections. Based on the study by Pan and Moehle [4] the maximum admissible drift (in rad) is a function of the applied shear force on the slab-column connection:

15

$$
\psi_{s t, u}=\max \left\{0.005,0.035-0.05 \cdot \frac{V}{V_{R}}\right\}
$$

16

17 where $V_{R}$ is the punching strength of the slab-column connection according to Eq. A.2. 


\section{EC2 provisions for moment transfer in slab-column connections}

2 As ACI-318, EC2 [2] uses the eccentric shear transfer model for predicting the maximum 3 unbalanced moment. While ACI-318 [1] assumes a linear shear stress distribution along the 4 control perimeter, EC2 assumes that it is uniform. Therefore, for a given shear force $V$ and 5 moment $M$, the shear stress $v_{E}$ acting on the control perimeter of the slab-column connection 6 is:

$$
v_{E}=\frac{V}{b_{0 . E C 2} \cdot d}+\frac{k \cdot M}{W_{1} \cdot d}
$$

9 where $b_{0, E C 2}$ is the length of the control perimeter (located at a distance of $2 d$ from the column 10 face), $k$ is the column aspect ratio factor that is equal to 0.60 for square columns, and $W_{l}$ is a

11 geometric parameter calculated by taking moments about the centroid of the control perimeter 12 which for internal square columns under uniaxial bending is:

$$
W_{1}=2.5 \cdot c^{2}+4 \cdot c \cdot d+16 \cdot d^{2}+2 \pi \cdot c \cdot d
$$

14

15 The maximum permissible shear stress $v_{R}$ acting on the control perimeter is:

16

$$
v_{R}=0.18 \cdot \zeta \cdot\left(100 \cdot \rho_{l} \cdot f_{c}\right)^{1 / 3}
$$

17

18 where $\zeta$ is a coefficient to take into account the size effect (equal to $1+\sqrt{200 / d} \leq 2.0$ ) and $\rho_{l}$ is

19 the flexural reinforcement ratio of the slab. The moment capacity for a given $\mathrm{V}$ can therefore

20 be calculated by substituting $v_{E}$ by $v_{R}$ in Eq. A.5 and solving for $M$. 


\section{$1 \quad$ MC2010 provisions for moment transfer in slab-column connections}

2 The punching formulation of Model Code 2010 is based on the Critical Shear Crack Theory

3 [36], which uses the following failure criterion:

4

$$
v_{R}=\min \left(\frac{1}{1.5+0.9 \cdot \psi \cdot d \cdot k_{d g}}, 0.6\right) \cdot \sqrt{f_{c}}
$$

5 where $k_{d g}=2 /\left(1+d_{g} / d_{g 0}\right) \geq 0.75$ and $d_{g 0}=16 \mathrm{~mm}$. For Level of Approximation II

6 (recommended for a typical design of new structures), the slab rotation can be estimated with

7 a simplified parabolic relationship, which is a function of the ratio of moment demand to 8 capacity [37]:

$$
\psi=1.5 \cdot \frac{r_{s}}{d} \cdot \frac{f_{y}}{E_{s}} \cdot\left(\frac{m_{s}}{m_{R}}\right)^{3 / 2}
$$

9 where $r_{s}$ is the radius of an isolated slab or $0.22 L$ in case of a continuous slab with regular

10 span lengths, $f_{y}$ and $E_{s}$ are the yield stress and modulus of elasticity of flexural reinforcement,

11 respectively. $m_{R}$ is the moment capacity of the slab and $m_{S}$ the average moment demand on

12 the column strip. For interior columns in slabs with sufficiently regular geometry, $m_{S}$ can be

13 estimated as $m_{S}=V \cdot\left(\frac{1}{8}+\frac{e}{2 \cdot b_{s}}\right)$, where $e=M_{d} / V_{d}$ is the load eccentricity and $b_{s}$ is the width of

14 the support strip.

15 Unbalanced moments are accounted for by reducing the length of the control perimeter 16 (situated at a distance of $d / 2$ from the column face) by the factor:

$$
k_{e}=\frac{1}{1+e / b}
$$

17 where $b$ is the diameter of a circle with the same surface as the region inside the basic control perimeter. 
1 The shear strength can therefore be computed using the following formula:

$$
V_{R}=v_{R} \cdot b_{0} \cdot d
$$

\section{References}

3

[36] Muttoni A. Punching shear strength of reinforced concrete slabs without transverse reinforcement. ACI Struct J 2008; (105)4: 440-450.

[37] Muttoni A, Fernández Ruiz M, Bentz EC, Foster SJ, Sigrist V. Background to the Model Code 2010 Shear Provisions - Part II Punching Shear. Struct Concrete 2013; (14)3: 195-203. 